\title{
Linking the evolution of development of stem vascular system in Nyctaginaceae and its correlation to habit and species diversification
}

\author{
Israel L. Cunha Neto ${ }^{1,2^{*}} \mathbb{0}$, Marcelo R. Pace ${ }^{3}$, Rebeca Hernández-Gutiérrez ${ }^{3}$ and Veronica Angyalossy ${ }^{1}$
}

\begin{abstract}
Background: Alternative patterns of secondary growth in stems of Nyctaginaceae is present in all growth habits of the family and have been known for a long time. However, the interpretation of types of cambial variants have been controversial, given that different authors have given them different developmental interpretations. The different growth habits coupled with an enormous stem anatomical diversity offers the unique opportunity to investigate the evolution of complex developments, to address how these anatomies shifted within habits, and how the acquisition of novel cambial variants and habit transitions impacted the diversification of the family.
\end{abstract}

Methods: We integrated developmental data with a phylogenetic framework to investigate the diversity and evolution of stem anatomy in Nyctaginaceae using phylogenetic comparative methods, reconstructing ancestral states, and examining whether anatomical shifts correspond to species diversification rate shifts in the family.

Results: Two types of cambial variants, interxylary phloem and successive cambia, were recorded in Nyctaginaceae, which result from four different ontogenies. These ontogenetic trajectories depart from two distinct primary vascular structures (regular or polycyclic eustele) yet, they contain shared developmental stages which generate stem morphologies with deconstructed boundaries of morphological categories (continuum morphology). Unlike our a priori hypotheses, interxylary phloem is reconstructed as the ancestral character for the family, with three ontogenies characterized as successive cambia evolving in few taxa. Cambial variants are not contingent on habits, and their transitions are independent from species diversification.

Conclusions: Our findings suggest that multiple developmental mechanisms, such as heterochrony and heterotopy, generate the transitions between interxylary phloem and successive cambia. Intermediate between these two extremes are present in Nyctaginaceae, suggesting a continuum morphology across the family as a generator of anatomical diversity.

Keywords: Anatomy, BAMM, Caryophyllales, Continuum morphology, Developmental processes, Evolution, Ontogeny, Vascular tissues

\footnotetext{
*Correspondence: israellopescn@gmail.com; i.cunhaneto@cornell.edu ${ }^{1}$ Laboratório de Anatomia Vegetal, Departamento de Botânica, Instituto de Biociências, Universidade de São Paulo, Rua do Matão 277, São Paulo, SP, Brazil

Full list of author information is available at the end of the article
}

\section{Background}

In the context of evolutionary developmental biology and phylogenetic research, morphological and anatomical comparative studies have played a major role in unravelling the complexity and diversity of both living and fossil original author(s) and the source, provide a link to the Creative Commons licence, and indicate if changes were made. The images or other third party material in this article are included in the article's Creative Commons licence, unless indicated otherwise in a credit line to the material. If material is not included in the article's Creative Commons licence and your intended use is not permitted by statutory regulation or exceeds the permitted use, you will need to obtain permission directly from the copyright holder. To view a copy of this licence, visit http://creativecommons.org/licenses/by/4.0/. The Creative Commons Public Domain Dedication waiver (http://creativeco mmons.org/publicdomain/zero/1.0/) applies to the data made available in this article, unless otherwise stated in a credit line to the data. 
organisms $[1,2]$. One of the fundamental pillars of this discipline is to investigate how developmental modifications contribute to the diversity of phenotypes in nature [1, 3-5]. In stem vascular development, previous studies have demonstrated different developmental programmes interacting in the evolution of various anatomical architectures, which are linked to hydraulic and biomechanical functions critical to water and sugar transport, storage, sustain and flexibility [6-9]. Therefore, by studying the developmental patterns that generate the diversity of stem vascular systems within a phylogenetic context, we can learn about the evolutionary mechanisms that have shaped the evolution of plant stems.

Secondary growth derived from a circular bifacial vascular cambium producing both wood (secondary xylem) and inner bark (secondary phloem), i.e., regular secondary growth, is thought to have originated in the Carboniferous 330 million years ago in the common ancestor of progymnosperms, gymnosperms, and angiosperms [10-12]. Within this large, diverse lineage, known as the lignophytes, numerous alternatives to this regular growth have evolved [13-16]. Modifications from the regular growth may derive from a single cambium with differential activity across its girth and/or multiple cambia $[15,17-19]$. These alternative patterns of secondary growth produce diverse and complex stems architectures, also known as cambial variants [17, 18]. Many types of cambial variants are found in lineages containing lianas, although they also occur in trees, shrubs and herbs, aerial and underground organs $[19,20]$. While the development of certain cambial variants has been investigated in recent years, the evolutionary history underlying the formation of these complex patterns is still being accumulated. The few previous studies integrating stem anatomical data with a phylogenetic framework have reviewed how disparate macromorphologies evolved from regular anatomies $[8,9]$, showing that their evolution involved different developmental mechanisms, especially heterochrony. Nevertheless, much has yet to be investigated to understand the total realm of changes in developmental trajectories that can contribute to the major complexity and diversity of the vascular system of plants in phylogenetically distant lineages.

Nyctaginaceae comprises c. 400 species that grows in a wide range of habits from arid deserts to tropical rain forests across the Americas, Africa and Indo-Pacific [21, 22]. The family includes herbs, shrubs, climbing plants, trees and suffrutescent species [21,22]. Regardless of growth forms, the stem vascular anatomy of most Nyctaginaceae is remarkable for their polycyclic eustele [23] and cambial variants that appear in mature stems [24-26]. Most other plant families only have cambial variants in certain clades or their lianescent taxa (Malpighiaceae [27]; Sapindaceae
$[9,28])$, although they are also found in self-supporting plants derived from lianescent ancestors (Bignoniaceae [8]; Convolvulaceae [29]). According to Gianoli [30, 31], the evolution of climbing habit increased the species richness of clades compared to their non-climbing sister groups. However, since many clades containing climbing plants (mostly lianas) are also characterized for showing cambial variants, we asked whether the shifts in habit or the evolution of cambial variants is what explains the increase in species diversity. Given that Nyctaginaceae have a wide diversity of habits and because all lineages have cambial variants, the family is perfect to test if the transition to the lianescent habit or the evolution of cambial variants promotes species diversification or not.

Distinct types of cambial variants (i.e., interxylary phloem and successive cambia) have been reported for Nyctaginaceae and more recently, through detailed ontogenetic studies, taxa initially described as having successive cambia were demonstrated to have interxylary phloem instead [32]. However, for a long time, the understanding of anatomical and developmental diversity of the vascular system in Nyctaginaceae had been limited given the absence of ontogenetic studies in a broader taxonomic scale. Most previous work have focused on the ornamental charismatic taxa, such as Bougainvillea and Mirabilis [25, 26, 33, 34]. In this study, we investigated the developmental processes that generate disparate vascular architectures throughout the family which is likely independent of habits and habitats.

Here, we compared stem development in the context of a well-supported phylogenetic hypothesis to understand how developmental processes evolved over time and shaped the diversity of stem architectures in Nyctaginaceae. Among the findings we highlight: (i) the anatomical changes underlying the evolution of four ontogenetic trajectories in stem development; (ii) the anatomical, developmental and evolutionary lability of vascular meristems, especially the vascular cambium; and (iii) the significance of developmental mechanisms for evolutionary diversity of stem anatomical architectures. In addition, we evaluated whether species diversification rates have changed in Nyctaginaceae to explore the potential impact of both the multiple transitions in vascular anatomies and the lianescent habit in the diversification of the family.

\section{Materials and methods}

\section{Taxon sampling and anatomical analysis}

This study represents the broadest taxonomic sampling for stem anatomical studies in Nyctaginaceae to date. Stem samples of 55 species ( 75 specimens) from 25 genera were collected, representing all major clades within the family, based on the most recent phylogenies for the group [21, 22, 35, 36]. Specimens were obtained 
mostly from field collections in different countries in both North and South America (Additional file 1: Table S1). Additional samples were obtained from dried stems from either herbarium vouchers or wood collections (Additional file 1: Table S1).

Samples from living plants were harvested at different heights of the stem to ensure that different developmental stages would not be missed. For herbs, complete stems were collected; for shrubs, lianas and scandentshrubs, samples were obtained at the base of the plant and at least three different heights towards the shoot apex. For trees, we collected trunk samples at c. $1.30 \mathrm{~m}$ height and at different heights of selected branches. See Additional file 1: Table S1 for information on stem diameter for each specimen.

For the ontogenetic analyses, 27 species belonging to 22 genera of Nyctaginaceae were selected to account for all the variation both in terms of their phylogenetic distribution and anatomical patterns (Additional file 1: Table S1). For these species, sections were taken from different internodes beginning at the shoot apex until reaching the fully developed stem. For the remaining species, analyses of adult stems (the most developed stem available, from fully grown plants) were carried out to ensure the cambial variant types studied previously in detail were consistent.

During field work the samples were immediately fixed in FAA 50 (10\% formalin, $5 \%$ acetic acid, 50\% ethanol) and then transferred to a solution of $70 \%$ ethanol [37]. Anatomical sections were obtained following two different procedures: (i) young and small stems samples were dehydrated in an ethanol series, embedded in Historesin (Leica Mycrosystem, Wetzlar, Germany), sectioned in a rotary microtome (Leica RM2145, Nussloch, Eisfeld, Germany), and stained in $0.05 \%$ toluidine blue in glacial acetic buffer at $\mathrm{pH} 4.7$ [38]; (ii) adult and large samples were softened in $5 \%$ ethylenediamine for up to 2 days [39], embedded in polyethylene glycol 1500, sectioned in a sliding microtome (Leica SM2010R, Nussloch, Eisfeld, Germany) [40, 41] and double stained in $1 \%$ astra blue and $1 \%$ safranine [42]. Sections were mounted with coverslip in Canada Balsam or Entellan ${ }^{\circledR}$ synthetic resin (Merck KGaA, Darmstadt, Germany) to make permanent slides.

\section{Phylogenetic framework, ancestral state reconstructions}

To estimate the evolutionary history of ontogenetic pathways, we applied an ancestral state reconstruction using the same phylogenetic tree applied by Cunha Neto et al. [23] under Maximum Likelihood (ML) assumptions as implemented in Mesquite version 3.5 [43].

\section{Diversification analysis \\ Divergence times}

To estimate the age of Nyctaginaceae, we conducted a Bayesian inference with BEAST v.2.6.5 [44], using two secondary calibrations derived from a thorough study of the divergence times of the angiosperm families [45]. We applied a uniform prior distribution to calibrate the root of the tree corresponding to the stem age of a group comprising Gisekiaceae and Nyctaginaceae, where the maximum value of the distribution was 83.6 Ma (Million years ago), and the minimum value was $52 \mathrm{Ma}$. We also applied a uniform prior distribution to calibrate the crown node of Nyctaginaceae, with a maximum value of $47.59 \mathrm{Ma}$ and minimum value of 18.12. In BEAUti, we assigned a molecular substitution model as GTR + G, using empirical base frequencies, molecular clock set as uncorrelated with rates obtained from a log-normal distribution (UCLN; [46]), and a birth-death tree prior. We ran two independent analyses, each with 400 million generations, sampling parameters every 10,000 generations. We corroborated the correct mixing of the Markovian chains in Tracer v.1.6 [47], where the Effective Sample Size (ESS) was equal or higher than 200 for all the parameters. We obtained the Maximum Clade Credibility (MCC) tree with TreeAnnotator v.2.6.5 (beast2.org/treeannotator). The analyses in BEAST2 were performed in the server BEAGLE of the Instituto de Biología (Universidad Nacional Autónoma de México). The monotypic Caribea littoralis Alain was excluded from the diversification analysis given the poor morphological and phylogenetic information on this enigmatic taxon [35].

\section{Diversification rate estimation}

Using the time-calibrated phylogeny (MCC tree), we evaluated whether there have been changes or shifts in the diversification rate through time and among lineages. The diversification rate corresponds to the net number of species/lineages generated per time unit (speciation) considering the extinction [48, 49]. For this, we implemented a Bayesian analysis of macroevolutionary mixtures (BAMM v.2.5.0; [50]). BAMM estimates diversification rate shifts under a compound Poisson process through time and among lineages, using reversible-jump Markov chain Monte Carlo (rjMCMC) samplers to evaluate models that vary in the number of shifts proposed [50]. We selected a set of priors calculated in the R package BAMMtools [51, 52] for the speciation and extinction initial values. We specified a proportion of taxon sampling to consider the missing species of Nyctaginaceae and outgroups. We ran the analysis for 100 million generations. 
We evaluated the convergence of chains and with the package coda [53] we corroborated that the ESS of the MCMC was 200 or above.

\section{Trait-dependent diversification}

To directly evaluate the contribution of characters in the diversification of Nyctaginaceae, we applied the Hidden State Speciation and Extinction method (HiSSE v.2.1.1; [53, 54]) for three characters, habit (self-supporting or climbing), eustele type (regular or polycyclic), and secondary growth (regular or variant). Using the dated phylogeny, we tested five models that varied in the relationship of the diversification rate and the observed, focal character. First, we evaluated a model, where diversification rates do not change across the phylogeny (Null). The second model tests two regimes of diversification rate that directly depend on the focal trait (BiSSElike model), similar to the BiSSE method [55]. The third model evaluates the relationship of the focal trait and another unobserved character (HiSSE, with two hidden states). This is to evaluate the relative contribution of the focal trait to the diversification. Finally, following Beaulieu and O'Meara [54], we tested two models of character-independent diversification (CID) allowing diversification rate to vary across the phylogeny, but independently from the focal trait. One of these models has two parameters of diversification rate (CID2), and the other has four (CID4), comparable to BiSSE-like and HiSSE models, respectively. Net diversification rate was obtained through turnover rate (default) and the extinction fraction. In all models, the extinction fraction was constrained to have the same rate for all the character states, the free parameters were the turnover rate and the transitions between character states. Missing species were considered in the models by accounting for the proportion of sampled species relative to the existing species displaying each of the two states. To select models that better explain the variation of the data, we obtained the Akaike weights to compare the relative likelihood of each model. Character data set (Additional file 2: Table S2) and parameter settings (Additional file 3: $\mathrm{R}$ script) can be found in Additional files 2, 3 .

\section{Terminology}

As the range of terms related to the vascular system in Nyctaginaceae is highly diverse, we here define the terminology used in the present study (see Glossary).

\section{Results}

Four ontogenetic pathways link procambium to cambium and cambial variants

In Nyctaginaceae, the stems may present two types of eustele, the regular or the polycyclic (with medullary bundles) (Fig. 1). The vascular system is also characterized by a distinguishable pericycle that can be uni- to multiseriate and which is divided into a portion of lignified cells and other that remains parenchymatous (Fig. 1). In mature stems, two types of cambial variants can be recognized, i.e., successive cambia and interxylary phloem, which derive from four different ontogenies (Fig. 1). Interestingly, representatives of all lineages of the family present variant vascular anatomies during secondary growth. Below we detail each of these ontogenies.

\section{Ontogeny 1 (summarized from Cunha Neto et al. [32])- Steps: (i) polycyclic eustele, (ii) vascular cambium, (iii) phloem strands, and (iv) interxylary phloem (Figs. 1A, 2A-E)}

This developmental pathway begins with a polycyclic eustele (reviewed by Cunha Neto [23])-medullary bundles + continuous cylindrical procambium (CCP) (Figs. 1A and 2A). This CCP is constituted by fascicular regions that produce vascular bundles, and interfascicular regions; both produce the cambium (Fig. 2A, B). After vascular bundles are formed from the CCP, a cambium is established from the procambium between primary xylem and phloem (Fig. 2B). This cambium presents an irregular activity leading to the formation of secondary xylem and phloem derivatives at different rates along the stem circumference, which results in the formation of phloem strands (Fig. 2C). Subsequently, these phloem strands are overarched by cambial segments originated by differentiation of the axial phloem parenchyma, called the coalescent (arching) cambium, and formed in continuity with the main cambium (Fig. 2C). This cambium produces secondary

\footnotetext{
(See figure on next page.)

Fig. 1 Diversity of stem ontogenies in Nyctaginaceae, illustrating developmental steps from eustele types to cambial variants. A Ontogeny 1 (interxylary phloem): polycyclic eustele, cambium from the CCP, phloem strands with different arrangements, illustrated by Colignonia glomerato (upper) forming bands and Pisonia aculeata (lower) forming phloem islands. B Ontogeny 2 (successive cambia): regular eustele, extra-fascicular cambium derived from the pericycle, additional successive bands or rings; Leucaster caniflorus. C Ontogeny 3 (successive cambia): regular eustele, regular cambium, new cambium formed de novo from the pericycle, additional successive bands or rings; Reichenbachia hirsuta. D Ontogeny 4 (successive cambia): polycyclic eustele, regular cambium derived from the CCP, new cambium formed de novo from the pericycle, additional small bands or rings of successive cambia; Allionia incarnata (upper) and Okenia hypogaea (lower). Drawing: Marcelo Kubo
} 


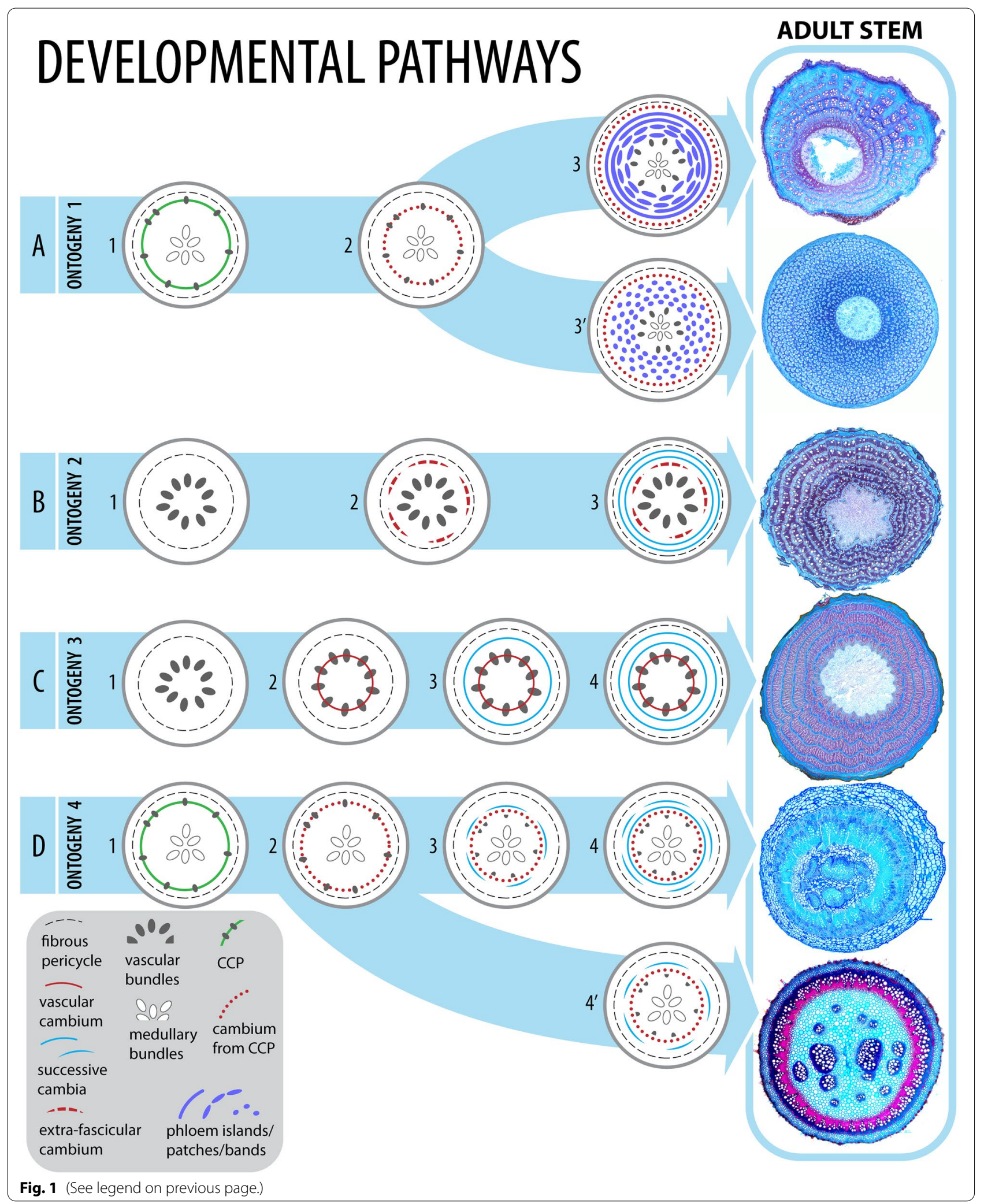




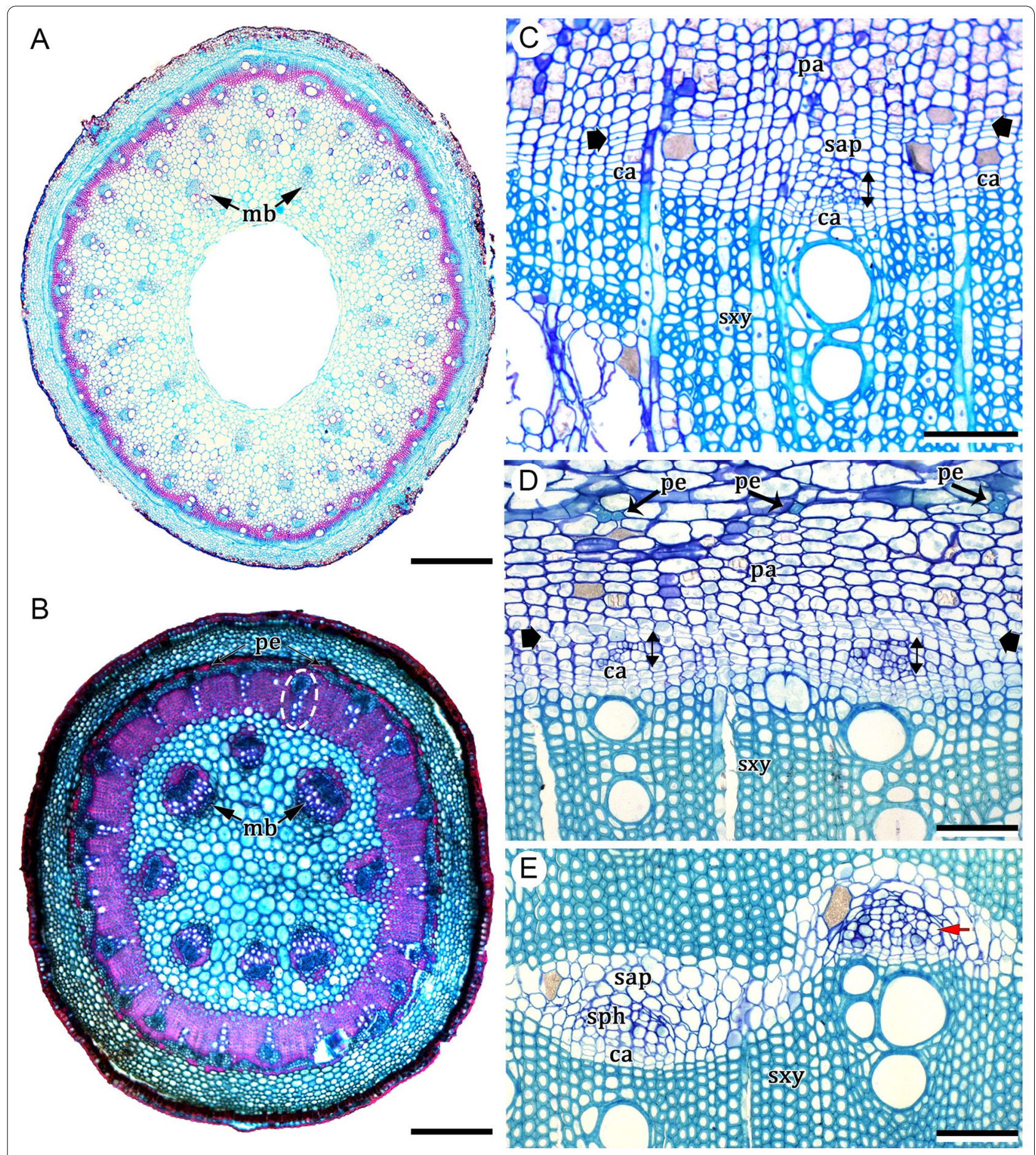

Fig. 2 Development of interxylary phloem (ontogeny 1). A Colignonia glomerata, young stem showing polycyclic eustele and the transition from primary to secondary growth. B Guapira pernambucensis, stem in early secondary growth; note the vascular bundles (ellipse) formed by the CCP, whose phloem will be the first phloem island. C Pisonia aculeata, irregular activity of the cambium which results in phloem islands (double arrows) after the development of the coalescent (arching) cambium (thick arrows). Note that the coalescent cambium is originated from the axial phloem parenchyma in continuity with the original cambium. D, E Guapira pernambucensis. D Arching cambium enclosing two phloem islands. E Two phloem islands formed by secondary conducting phloem and sheathing axial parenchyma. The red arrow indicates a sieve-tube element. Scale bars: $200 \mu \mathrm{m}$ (A-C); $100 \mu \mathrm{m}$ (D, E). ca cambium, mb medullary bundles, pa axial phloem parenchyma, pe pericyclic fibers, sap sheathing axial parenchyma, sph secondary conducting phloem, sxy secondary xylem. A, B Stained with astra blue and safranin. C, E Stained with toluidine blue 
xylem inwards and phloem outwards. These new tissues enclose the islands of phloem, constituted mainly by conducting cells and axial phloem parenchyma (Fig. 2C, D) which here we denominate sheathing axial parenchyma (Fig. 2E). This process occurs repeatedly in the cambial zone and, as a result, many phloem strands are formed with the original cambial segment embedded within the secondary xylem (Fig. 2E).

The cambial variant described above characterizes the formation of interxylary phloem. In Nyctaginaceae, this pattern produces disparate stem architectures ranging from well-defined phloem islands with less sheathing axial parenchyma to long concentric bands of phloem and much sheathing axial parenchyma arranged tangentially (Fig. 1A). Intermediates between these two types forming phloem strands produced by longer coalescent cambium and confluences of phloem strands (patches) also occur.

Ontogeny 1 is the most common type within Nyctaginaceae, occurring in genera and species of various growth habits and from five out of the seven tribes, i.e., Boldoeae, Bougainvillea, Colignonieae, Nyctagineae and Pisonieae.

\section{Ontogeny 2-Steps: (i) regular eustele, (ii) extra-fascicular} cambium, and (iii) successive cambia (Figs. 1B, 3A-E, 4A-C) This pattern differs from ontogeny 3 (see description below) for not forming a regular cambium (derived from the procambium remnants of vascular bundles), even though it starts stem development with a regular eustele (Fig. 3A). The genera under this ontogeny lack medullary bundles. Instead of forming a regular cambium, the first cambium differentiated externally to the vascular bundles (i.e., extra-fascicular cambium), giving rise to secondary xylem produced internally and secondary phloem formed to the outside (Fig. 3B-E). This variant cambium differentiates from a meristematic zone formed by divisions of the pericyclic parenchyma cells located between the primary phloem and the fibrous pericycle (Fig. 3C). Subsequently, additional cambia are formed outwards from remaining cells of the previous meristematic zone (Fig. 3E), whereas some parenchyma cells produced by the meristematic zone will constitute what here we call tangential conjunctive tissue between two vascular increments (Figs. 3A, $4 \mathrm{~A}-\mathrm{C}$ ). At maturity, the increments of successive cambia can appear wavy (Fig. 4B), or more or less concentric (Figs. 1C, 4C). In any case, sieve-tube elements and their companion cells are formed always at the opposite side of the vessel elements, while conjunctive parenchyma form an intricate network with the vascular rays (Fig. 4B-C).
Ontogeny 2 was observed in the genera Andradea, Leucaster and Ramisia, which are trees or lianas and all belonging to tribe Leucastereae.

\section{Ontogeny 3-Steps: (i) regular eustele, (ii) vascular cambium, (iii) installation of variant cambium, and (iv) successive cambia (Figs. 1C, 5A-D, 6A-D)}

This ontogeny initiates with a regular eustele (Fig. 5A). Similarly to species in ontogeny 2 , the species under this ontogeny lack medullary bundles. Later, a regular cambium develops from the fascicular and interfascicular cambium and starts to produce secondary tissues in the usual way, i.e., secondary xylem centripetally and secondary phloem centrifugally (Figs. 5A-D, 6A-D). Initially, the interfascicular cambium may produce mostly phloem axial parenchyma to the outside and produce xylem fibres, vessel and rays to the inside (Fig. 6C). After some period of regular growth, a new meristematic zone arises through subsequent divisions of pericyclic parenchyma cells outside of the primary phloem (Fig. 6A-C). Then, a new cambium (variant cambium) differentiates in the middle of the meristematic zone (Fig. 6B), producing secondary xylem and secondary phloem in the usual polarity (Fig. 6C, D). Subsequently, by the same mechanism of the first variant cambium, new cambia arise successively in centrifugal, concentric order, each originating from the outer derivatives of the preceding meristematic zone (Fig. 6D).

In mature stems, the tangential conjunctive tissue forms a network with narrow and wide vascular rays (Fig. 6E). The sieve-tube elements and their companion cells form mostly strands surrounded by the tangential conjunctive tissue, located at an opposite pole of the radially arranged vessel elements (Fig. 6E, F).

Ontogeny 3 was observed exclusively in the shrubby species of genus Reichenbachia (tribe Leucastereae).

\section{Ontogeny 4-Steps: (i) polycyclic eustele, (ii) vascular cambium, (iii) installation of variant cambium, and (iv) successive cambia (Figs. 1D, 7A-E)}

This ontogeny differs from ontogeny 3 for having a polycyclic eustele (Fig. 7A). As for ontogeny 1 (also with polycyclic eustele), a vascular cambium develops from the fascicular and interfascicular CCP, but in this case the cambium produces regular secondary xylem and phloem at relatively regular rates for some time (Fig. 7B, E). Later, divisions of the pericyclic parenchyma cells (Fig. 7C) form a meristematic zone, where new segments of cambia develop producing new vascular increments composed of variant secondary xylem and phloem in the usual polarity (Fig. 7D, E). 


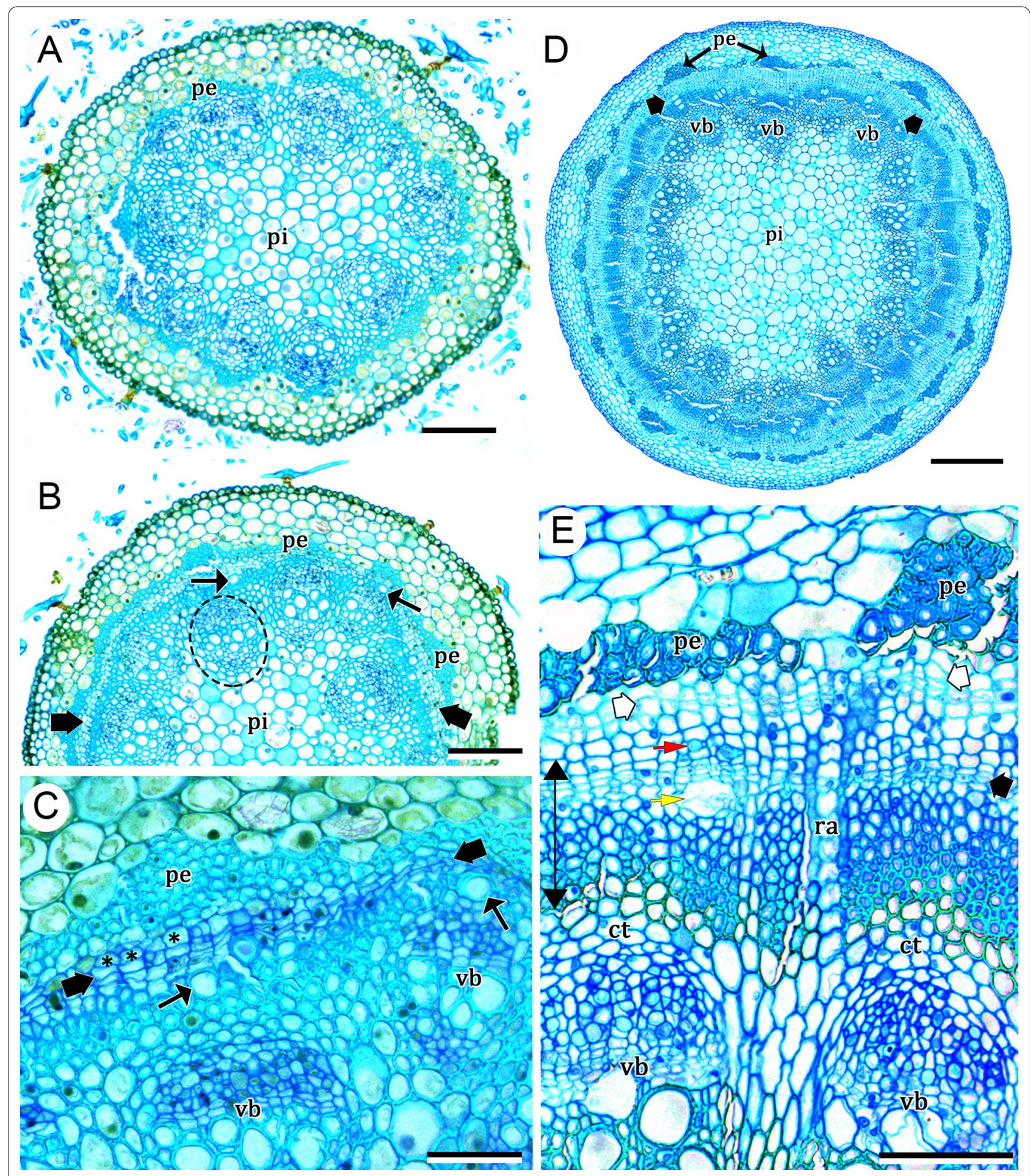

Fig. 3 Development of successive cambia in stems of Leucaster caniflorus and Ramisia brasiliensis (ontogeny 2). A-C Leucaster caniflorus. A Young stem with regular eustele. B Initiation of secondary growth through the extra-fascicular cambium (thick black arrows); note the first formed vessels of the secondary xylem (thin black arrows). C Detail of the extra-fascicular cambium (thick black arrows) and first formed vessels (thin black arrows); note the pericycle parenchyma cells (asterisks). D, E Ramisia brasiliensis. D Establishment of the extra-fascicular cambium (thick black arrows) outside the vascular bundles of the eustele. E Secondary vascular tissue (double arrow) originated from the extra-fascicular cambium (thick black arrow). The yellow arrow indicates a vessel element, and the red arrow indicates a sieve-tube element and its companion cell. Note the developing meristematic zone (white arrows) undergoing cell divisions that will give rise to the subsequent ring of successive cambia. The conjunctive parenchyma is also observed. Scale bars: $100 \mu \mathrm{m}(\mathbf{A}, \mathbf{B}, \mathbf{E}) ; 50 \mu \mathrm{m}(\mathbf{C}) ; 400 \mu \mathrm{m}$ (D). ct conjunctive parenchyma, pe pericyclic fibres, pi pith, ra ray, vb vascular bundles of the regular eustele. $\mathbf{A}-\mathbf{E}$ Stained with toluidine blue 


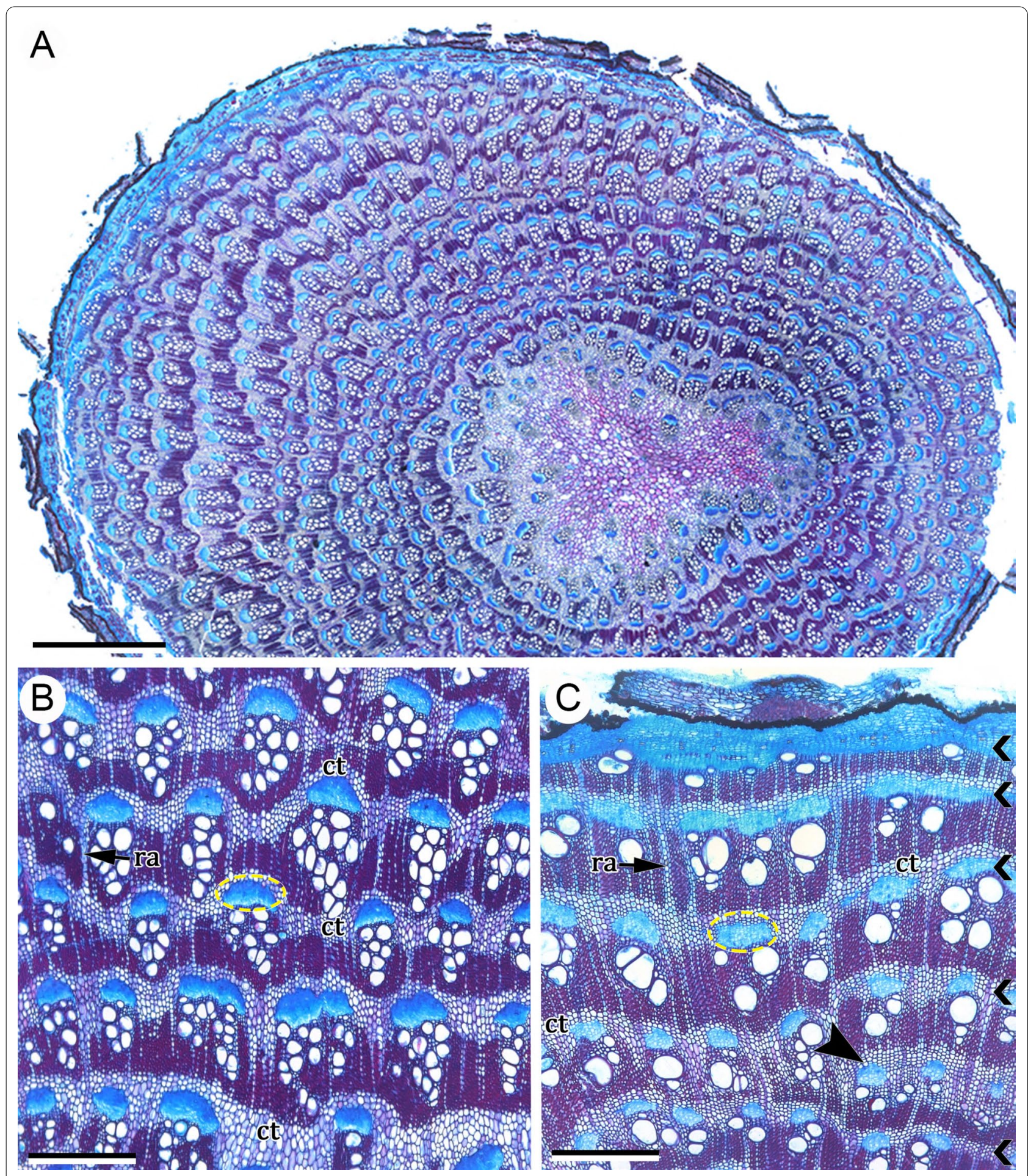

Fig. 4 Cross view of developed stems with successive cambia (ontogeny 2). A, B Andradea floribunda. C Leucaster caniflorus. A Adult stem showing several rings of successive cambia. B Detail of the successive cambia and their vascular products; the phloem form small strands (yellow ellipse). Note the wavy appearance of the vascular tissues. $\mathbf{C}$ Rings of successive cambia in more or less regular concentric arrangement (pointers); the arrowhead indicates an incomplete segment between the other upper and lower rings; note the phloem forming small strands (yellow ellipse). Scale bars: $2000 \mu \mathrm{m}$ (A); $500 \mu \mathrm{m}$ (A, B). ct conjunctive tissue, pe pericyclic fibres, pi pith, ra ray. A-C Stained with astra blue and safranin 


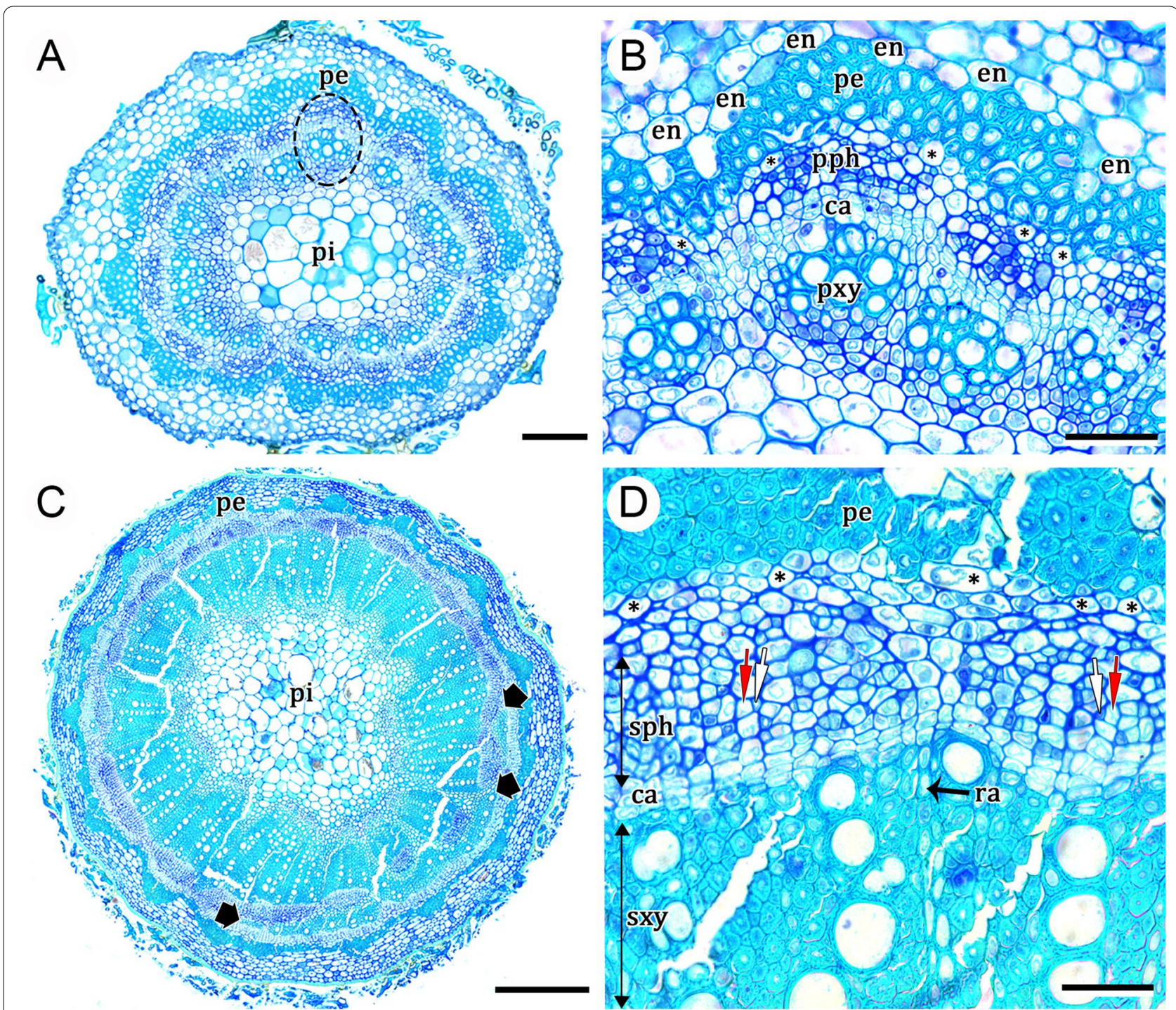

Fig. 5 Early stem development in Reichenbachia hirsuta (ontogeny 3). A Initial secondary growth derived from a regular eustele; the dashed ellipse indicates the position of a vascular bundle. B Detail of regular cambium and its derivatives, primary vascular tissues, fibrous pericycle and parenchymatous pericyclic cells (asterisks). C Stem during regular secondary growth, first variant cambium and its derivatives (thick arrow); see details in next Fig. 6A-D. D Regular cambium, secondary xylem and secondary phloem. Scale bars: 50 um (A-C); $400 \mu \mathrm{m}$ (D). Arrow (white), companion cell; Arrow (red), sieve-tube element; Asterisks, pericyclic parenchyma cells; ca regular cambium, en endodermis, mz meristematic zone, pe pericyclic fibres, pi pith, pph primary phloem, pxy primary xylem, ra ray, sph secondary phloem, sxy secondary xylem. A-D Stained with toluidine blue

Ontogeny 4 was found only in two monotypic genera (Allionia and Okenia) of herbaceous plants from tribe Nyctagineae. Although successive cambia establish in these plants, these species show relatively little secondary tissues even in the most developed stems, as seen in Allionia incarnata (Fig. 1D; reviewed by Cunha Neto [56]) and Okenia hypogaea (Figs. 1D, 7B). In Allionia, one or two complete rings of vascular increments are possible, whereas in Okenia hypogaea, only small cambial segments of first order were seen in the most developed stems (Figs. 1D, 7B).

\section{Character mapping and ancestral state reconstruction}

To assess the evolution of stem development in Nyctaginaceae, the ontogenies were mapped onto the current phylogeny of the family. Each of the four ontogenetic pathways were delimited as character states. The phylogenetic analysis showed that ontogeny 1 (polycyclic 

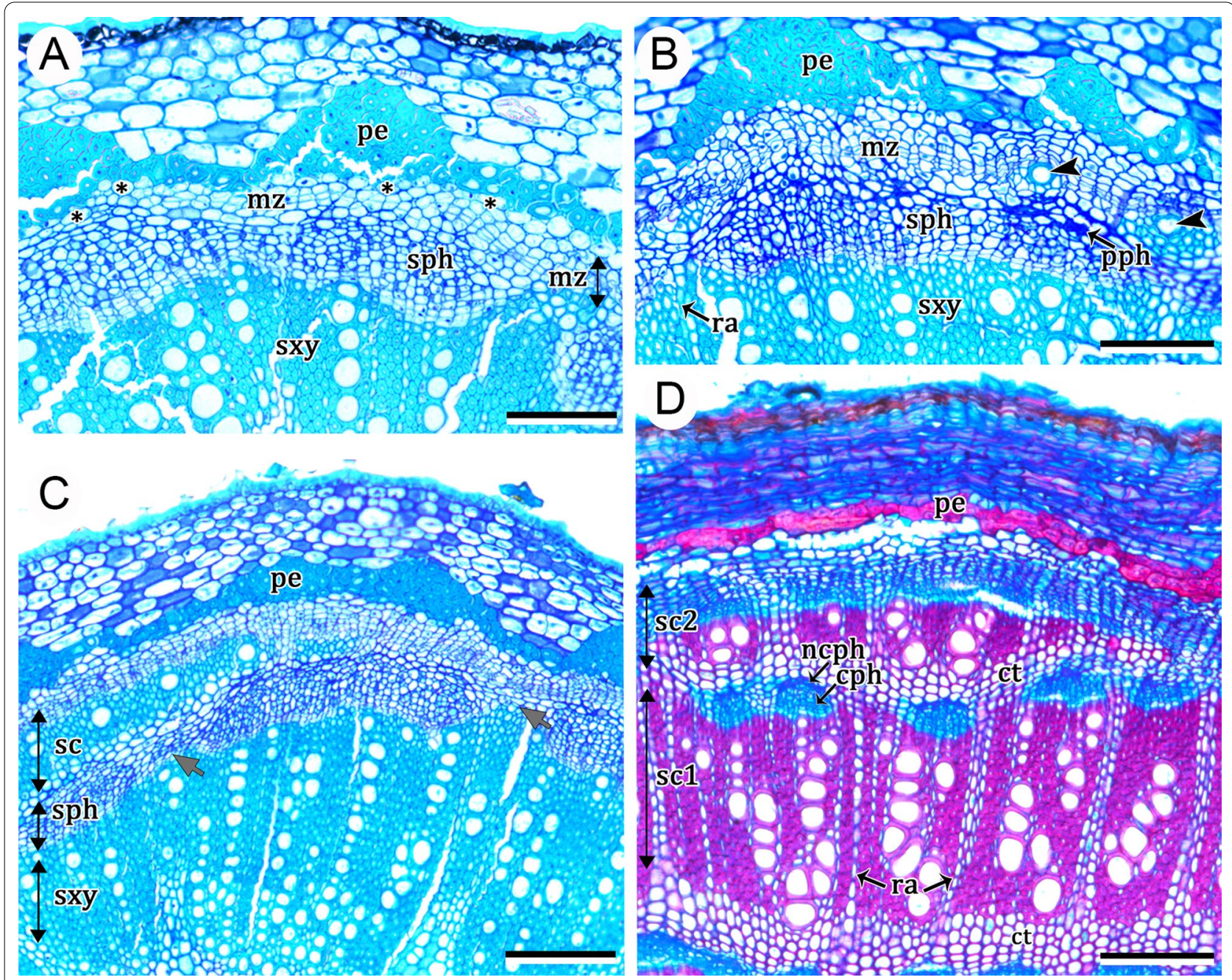

Fig. 6 Development of successive cambia in stems of Reichenbachia hirsuta (ontogeny 3). A Meristematic zone and pericyclic cells that remain parenchymatous (asterisks). B Development of the first variant cambium within the meristematic zone. Arrowheads indicate vessel elements. C First ring of successive cambia with their variant xylem and variant phloem (sc). Initially, the interfascicular cambium (grey arrow) produces mostly phloem axial parenchyma to the outside and xylem fibers to the inner side. D Mature stem showing two rings of successive cambia with conjunctive tissue between them. Scale bars: $100 \mu \mathrm{m}$ (A-C); $200 \mu \mathrm{m}$ (D). cph conducting phloem, ct conjunctive tissue, ncph non-conducting phloem, mz meristematic zone, pe pericyclic fibres, pph primary phloem (crushed), ra ray, sc sc1 e sc2, increments of successive cambia, sph secondary phloem, sxy secondary xylem. A-C Stained with toluidine blue. D Stained with astra blue and safranin

eustele + interxylary phloem) is the most common and was reconstructed as the ancestral state (79\% presence), with a few secondary losses (Fig. 8, e.g., Leucastereae, Nyctagineae). Ontogeny 4 (polycyclic eustele + successive cambia) evolved twice, being found in genera belonging to Nyctagineae that includes the majority of the herbaceous species, whereas ontogeny 2 (regular eustele + regular cambium + successive cambia) and ontogeny 3 (regular eustele + extra-fascicular cambium + successive cambia) evolved each only once, occurring in genera of tribe Leucastereae (the clade sister to the rest of the family) which is formed by shrubs, trees and/or lianas.

\section{Divergence times and diversification rate estimation}

We estimated the age of divergence of Nyctaginaceae and close relatives with BEAST2 (Fig. 9). We obtained the Maximum Clade Credibility tree (Fig. 9, Additional file 4: Nexus tree), which shows the mean age for the main nodes in the phylogeny. Table 1 shows the mean crown age estimates for the major clades and its associated credibility interval represented by the $95 \%$ Highest 


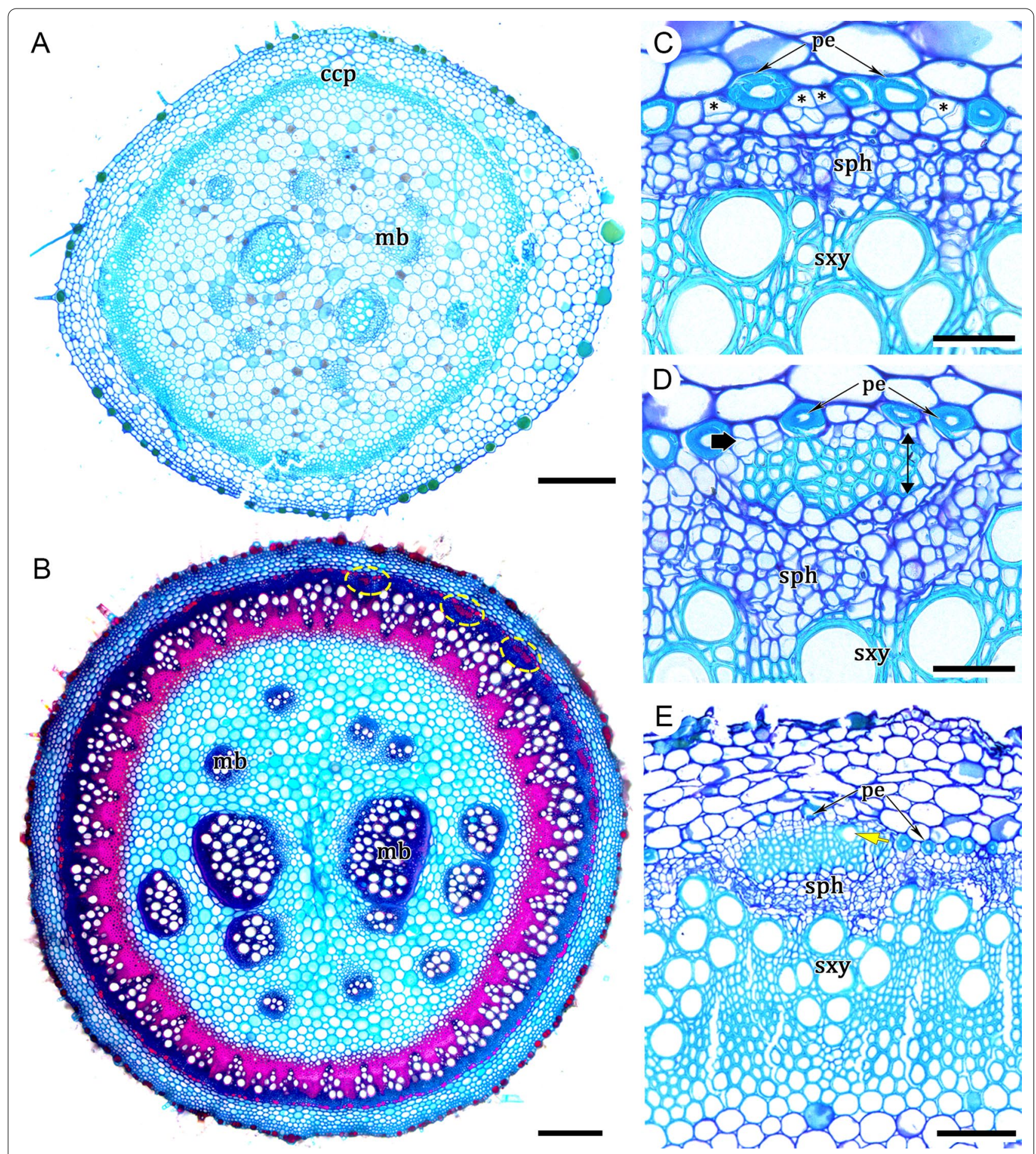

Fig. 7 Development of successive cambia in stems of Okenia hypogaea (ontogeny 4). A Primary growth with polycyclic eustele. B Stem with cambial variant. Dashed ellipses indicate the arcs of successive cambia; note medullary bundles in the pith. C Secondary xylem and secondary phloem, pericycle parenchyma undergoing cell division (asterisks) to form a meristematic zone, where new cambia will be formed. D Developing variant cambium (thick arrow) and variant xylem formed mostly by fibres (double arrow). E Developing arc of successive cambia showing variant xylem with first formed vessel (yellow arrow). Scale bars: $200 \mu \mathrm{m}$ (A); $400 \mu \mathrm{m}$ (B); $50 \mu \mathrm{m}$ (C, D); $100 \mu \mathrm{m}$ (E). ccp cylindrical continuous procambium, mb medullary bundles, pe pericyclic fibers, sph secondary phloem, sxy secondary xylem. A, C-E Stained with toluidine blue. B Stained with astra blue and safranin 


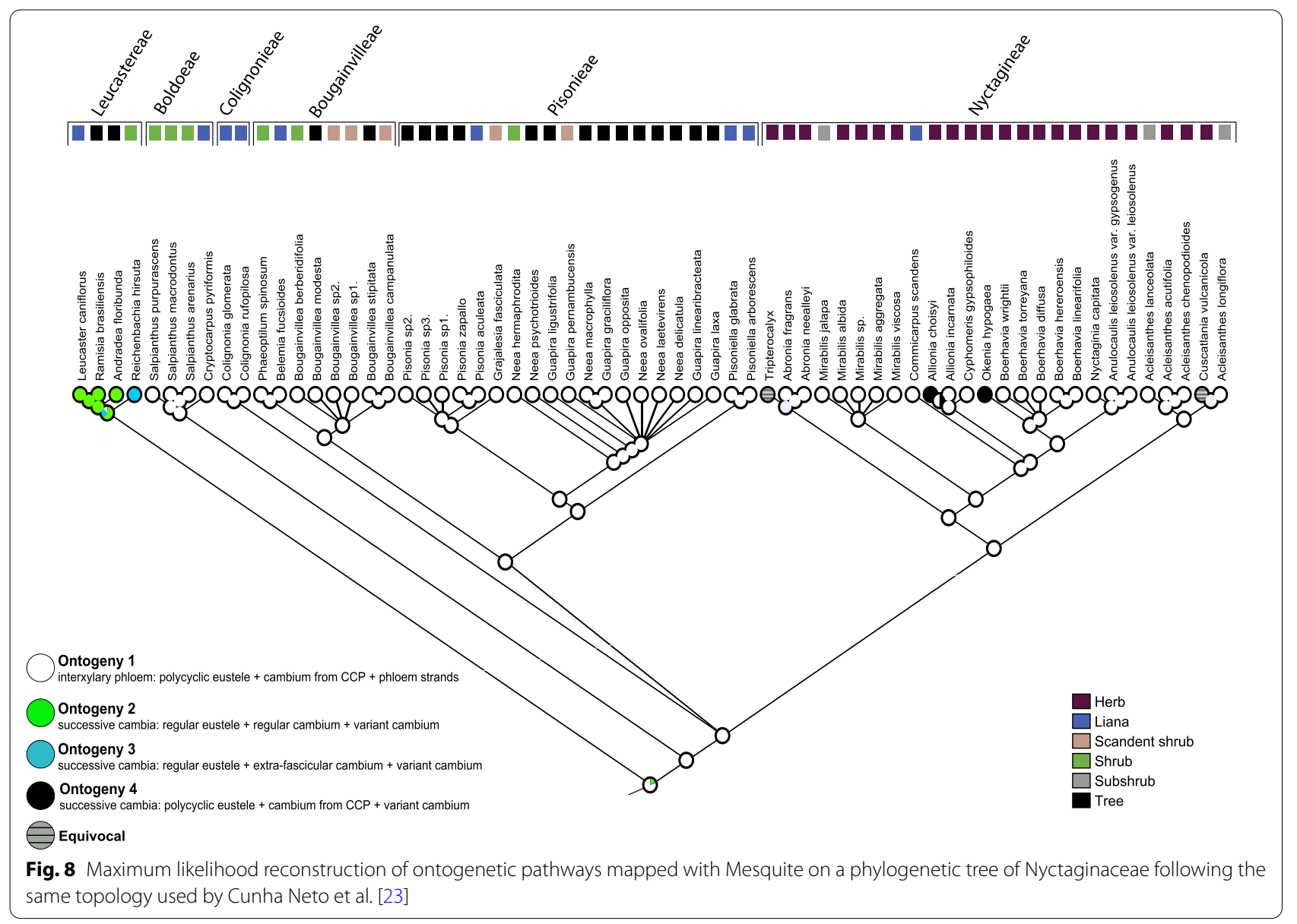

Posterior Density (HPD). Nyctaginaceae probably diverged from its sister group (stem age), Phytolaccaceae, $48 \mathrm{Ma}$ (HPD: 38.97-55.56 Ma) and diversified (crown age) 42.3 Ma (HPD: 32.82-47.59 Ma), both events occurring at the Middle Eocene.

The estimation of diversification rate shifts implemented in BAMM resulted in a set of configurations, each configuration represents a group of possible rate shifts occurring in the phylogenetic tree at different times. The Maximum a posteriori probability (MAP) configuration was obtained in the R package BAMMtools and is observed in the phylorates plot shown in Fig. 10, where the estimated rate at each segment of the branches is the mean of the marginal posterior density of the diversification rate, and the shifts are marked by a green circle. The MAP includes the most frequent configuration with two shifts in the diversification rate (i.e., speciation minus extinction; green circles in Fig. 10; check Additional file 5: Fig. S1 for all most credible shift sets recovered by BAMM). The results indicate one diversification shift derived from a rise in the speciation rate alone in the clade that includes Pisonieae-Bougainvilleae-Nyctagineae, and another diversification increase derived from rises in both speciation and extinction rates in bulk of Commicarpus, as observed in the speciation rate and in the extinction rate separately.

Table 2 shows the results from the trait-dependent diversification analysis and model comparison. For habit and secondary growth, the preferred model was the character-independent diversification (CID2). In turn, for eustele type, the preferred model was a trait-dependent diversification with two diversification regimes (BiSSElike). This indicates that eustele type had a relationship with diversification rate, being the polycyclic eustele associated to elevated diversification rate compared to regular eustele (Fig. 11). 


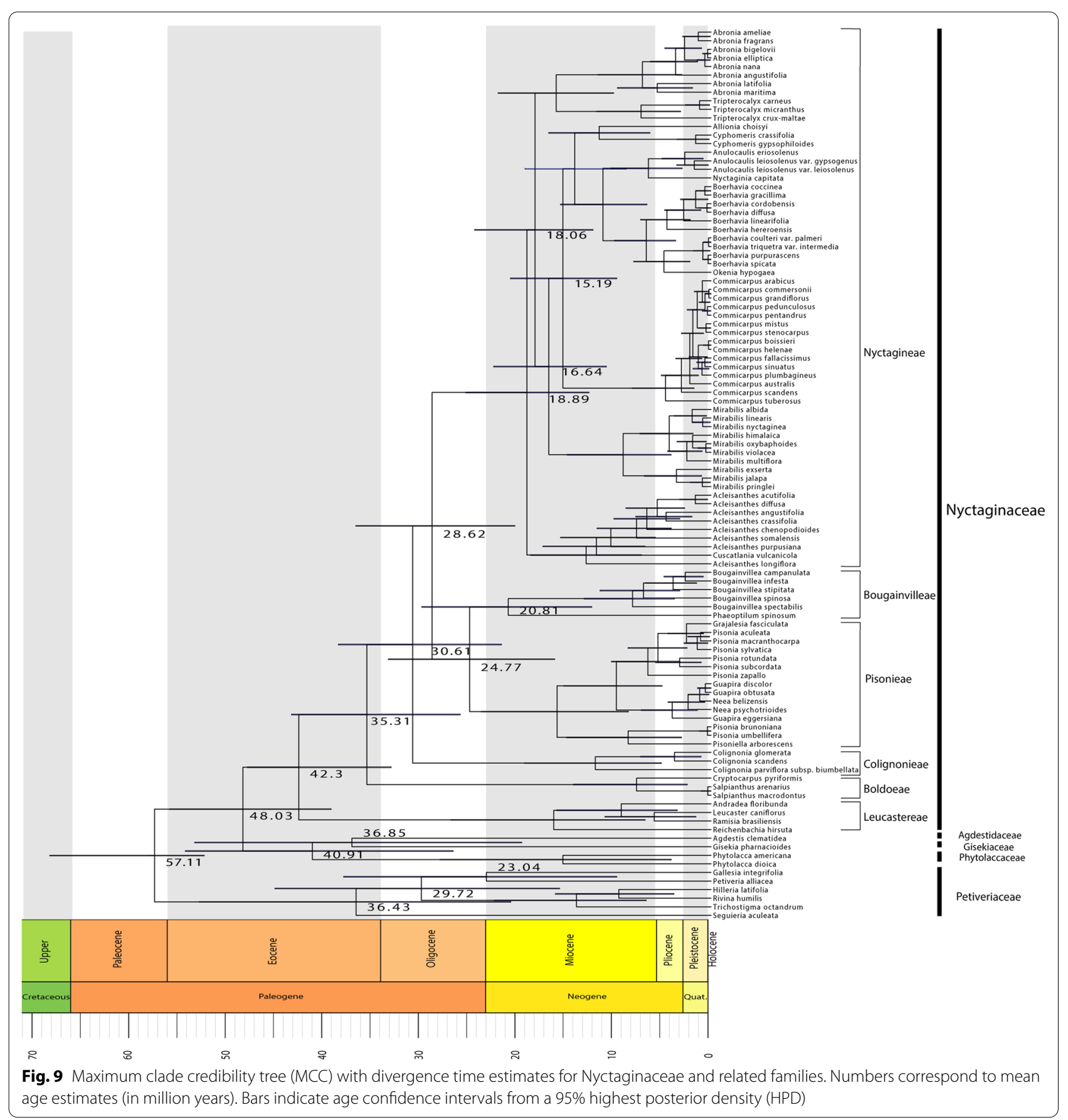

Table 1 Divergence-time estimation of mean crown ages in Million years $(\mathrm{Ma})$

\begin{tabular}{lll}
\hline Family & Crown age (Ma) & 95\% HPD \\
\hline Nyctaginaceae & 42.3 & $32.82-47.59$ \\
Phytolaccaceae & 40.91 & $26.45-53.95$
\end{tabular}

Highest posterior density intervall (95\% HPD)

\section{Discussion}

The evolution of cambial variants in Nyctaginaceae represents an example of continuum morphology

Because evolution can be seen as the transformation of ontogenies, many authors have argued that plant morphology is better understood under more dynamic and process thinking than the typological view of classical 


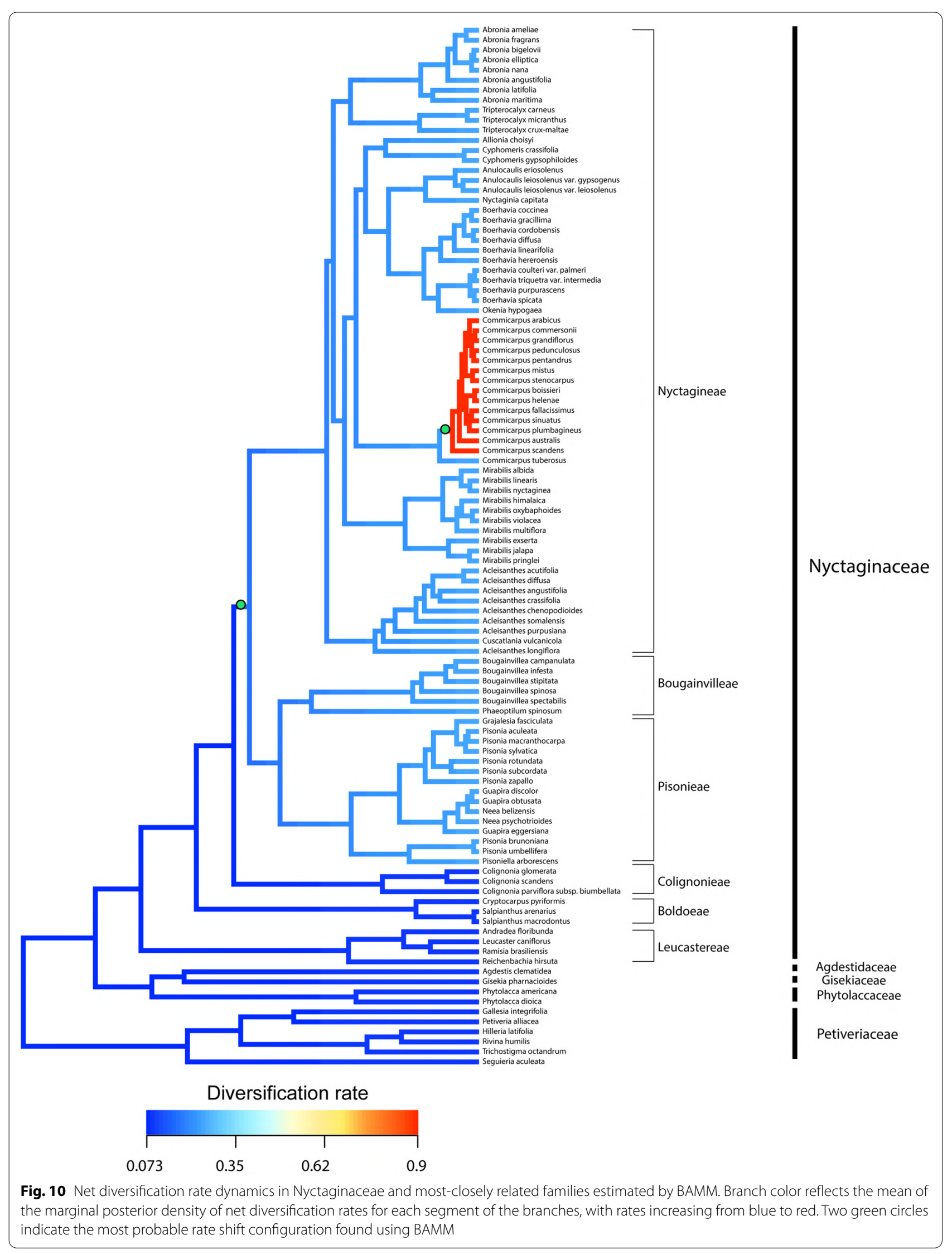


Table 2 Model comparison from the trait-dependent diversification analysis

\begin{tabular}{|c|c|c|c|c|c|c|c|c|c|}
\hline \multirow[t]{2}{*}{ Model } & \multicolumn{3}{|l|}{ Habit } & \multicolumn{3}{|c|}{ Eustele type } & \multicolumn{3}{|c|}{ Secondary growth } \\
\hline & loglik & AICc & $\mathrm{AlCw}$ & loglik & AICc & $\mathrm{AICw}$ & loglik & $\mathrm{AICc}$ & $\mathrm{AICw}$ \\
\hline Null & -366.56 & 741.53 & 0.00 & -322.19 & 652.79 & 0.02 & -320.53 & 649.47 & 0.00 \\
\hline BiSSE-like & -366.53 & 743.66 & 0.00 & -316.99 & 644.58 & 0.91 & -318.61 & 647.73 & 0.00 \\
\hline HiSSE & -350.74 & 723.85 & 0.41 & -315.52 & 653.41 & 0.01 & -309.64 & 641.71 & 0.04 \\
\hline CID2 & -355.41 & 723.68 & 0.44 & -318.70 & 650.28 & 0.05 & -311.45 & 635.79 & 0.84 \\
\hline CID4 & -354.13 & 725.77 & 0.16 & -317.77 & 653.05 & 0.01 & -311.06 & 639.69 & 0.12 \\
\hline
\end{tabular}

Bold rows indicate the preferred model for each evaluated character

loglik log-likelihood, AICc corrected Akaike score, AICW Akaike weight

morphologists (e.g., Wilhelm Troll, Donald Kaplan) [57, 58]. One of the alternative worldviews known as continuum morphology has been built through the works of several botanists, such as Agnes Arber [59] and Rolf Sattler [3, 60, 61]. This approach implies that the static view of plants having structures (such as organs or the different variants here) with clear cut boundaries seems no longer sufficient to explain plant morpho-anatomical diversity [57]. In contrast, the process and continuum morphology recognize plants as combinations of developmental processes or as dynamic continua, based on the acceptance of the partial homology concept $[59,61]$, which reiterates the blurry boundaries (mixed identities, fuzzy morphology) between what used to be considered as separate structural categories $[62,63]$. This means that diversity is more likely to result from quantitative rather than from qualitative differences in development, which leads to the identification of several intermediate forms between two categories [61]. The continuum approach may be as well the better way to look at the evolution of successive cambia from the interxylary phloem in Nyctaginaceae.

Although successive cambia and interxylary phloem are recognized in the literature as two types of cambial variants, their occurrence in Nyctaginaceae indicates that in some cases there is a blurry boundary delimitation between these two patterns-which are represented in two levels. First, plants with ontogeny 1 that are characterized with interxylary phloem may present phloem strands immersed within the xylem with intermediatelike arrangements, i.e., phloem islands, patches or bands. These arrangements result from different extensions of the coalescent cambium which is formed in continuity with the single cambium and encloses the phloem strands and sheathing axial parenchyma with diverse spatial distributions [32]. Given that in plants with bands the stem initiates forming phloem islands followed by patches and then bands, the development of this ontogeny itself indicates the existence of a continuum between these different stem macromorphologies. Second, the ontogenies characterized with successive cambia shows that the independent cambia form usually long tangential bands of vascular tissues similar to the interxylary phloem forming bands of other species of the family. The diverse topologies observed in plants with successive cambia which has received numerous attempts of subcategorization is another evidence of these blurry categories (Additional file 6: Table S4).

The continuum worldview has been applied especially in organ identity [62-65] but a parallel seems possible to be established with other biological systems (e.g., growth forms [66], photosynthetic pathways [67]), which are not framed around the distinctiveness of shoot organs. Here, for the first time, the diversity of cambial variants is interpreted under the concept of continuum morphology, although within the same organ. These observations for Nyctaginaceae enrich our understanding of these complex vascular morphologies, as it illustrates how ontogenies changed across evolutionary time producing intermediate forms that at some point can be distinguished as discrete categories.

\section{The origins and developments determining the cambial variants in Nyctaginaceae}

The recognition of interxylary phloem along with the occurrence of successive cambia is based primarily on their differences in development, i.e., single vs. multiple cambia, respectively [32], but these developmental pathways result in similar anatomies and can be considered to integrate into intermediate forms in Nyctaginaceae.

Here we identified that to the four ontogenies, all events of vascular development originated internally to the pericyclic fibres. These findings contradict the hypothesis that the cambial variants in Nyctaginaceae are formed from a meristem arising in the cortex [26, 33, 34, $68,69]$. Instead, all cambial variants originated from procambial-derived cells, corroborating previous findings [56, 70]. Therefore, successive cambia and interxylary phloem are evolutionarily and developmentally linked in Nyctaginaceae, because both the cambium giving rise to 


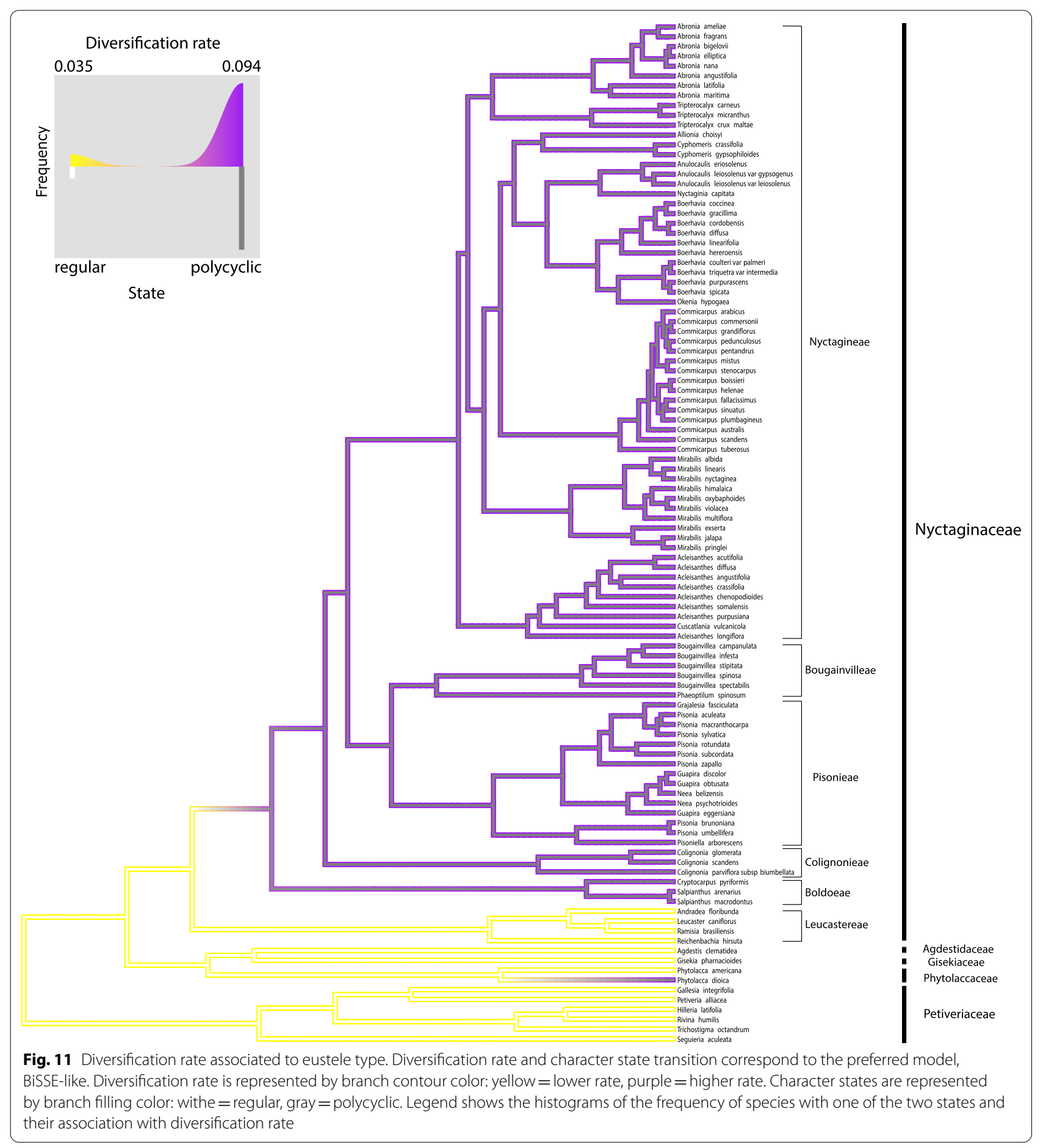

phloem strands within the secondary xylem (interxylary phloem) and the meristematic zone producing a de novo cambium (successive cambia) may be traced back to the procambium at some point in stem development.

Although the cambial variants in Nyctaginaceae have similar origins at the cell lineage level (i.e., procambium-derived cells), the eustele types and subsequent events in their development are diverse, leading to four distinct ontogenies. In a previous work we showed that the origin and development of interxylary phloem in Nyctaginaceae is similar to other groups, except for the fact that in this family they initiate with a polycyclic 
eustele [32]. Although ontogenies 2, 3 and 4 are characterized as successive cambia at maturity, they present different developmental stages. The developmental steps for Reichenbachia (ontogeny 3) are the same described in most families with this cambial variant, i.e., a new cambium is formed de novo (mostly but not always) from the pericycle in stems with regular eustele. This is the case of species both in the gymnosperms (e.g., Gnetum, Cycas[68]) and several families of angiosperms (e.g., Menispermaceae [71]; Convolvulaceae [29]; Sapindaceae [72]). On the other hand, successive cambia, as described in ontogenies 3 and 4, differ from the taxa mentioned above, because they either do not produce a regular cambium, forming an extra-fascicular cambium (ontogeny 2), or because the stem begins with a polycyclic eustele, and the first cambium is derived from the CCP instead of a regular cambium (ontogeny 4). It is important to highlight that the appearance of the extra-fascicular cambium, which is independent from the primary vasculature, corroborates the potential of perivascular tissues (i.e., the pericycle) to produce new meristems. Finally, this study also corroborates the idea that there are multiple origins (e.g., primary phloem, secondary phloem, cortex [29, 72-75]) and developmental trajectories that can lead to successive cambia, unlike the hypothesis of a universal phenomenon across different plant groups $[68,69,76]$.

\section{Nyctaginaceae stands out for having all extant lineages characterized by variant anatomies}

The ancestral state reconstruction presented here demonstrates that the ancestor of Nyctaginaceae already had cambial variant, with interxylary phloem (ontogeny 1) reconstructed as the most likely character state for the ancestral node of the family. This observation is remarkable, because it indicates that Nyctaginaceae is one of the few examples, where the cambial variants are present in all members and is shown to be shared with other members of the phytolaccoid clade, being likely plesiomorphic for Nyctaginaceae. In most families with cambial variants they appear only in one group, mostly in clades containing lianas or descending from lianas (e.g., Bignoniaceae, Convolvulaceae) $[8,9,28,77]$. Contrary to expectations, interxylary phloem (ontogeny 1 ) is the most common type of cambial variant in Nyctaginaceae, occurring in five out of seven tribes, including genera, such as Bougainvillea, Boerhavia, Mirabilis and Pisonia, which used to be classified as having successive cambia (reviewed by [32]). The ontogenies appeared only once, except for ontogeny 4 that evolved twice. The evolution of ontogenies 2 and 3 in members of Leucastereae is interesting, because the tribe has other morphological (e.g., type of trichomes, pollen and fruit- $[42,76,77])$ and vascular characters (e.g., type of stele, [23]) that are exclusive if compared to other lineages of the family. Curiously, from all stem ontogenies of Nyctaginaceae, Reichenbachia (ontogeny 3 ) is the only taxon following the commonly described development for successive cambia, i.e., regular eustele + regular cylinder + successive cambia $[29,71$, 72].

Ontogeny 4 is the only type with more than one evolution with two transitions in tribe Nyctagineae. The evolution of successive cambia in Allionia and Okenia is noteworthy for the fact that they are both small herbs with limited secondary growth in the regular cylinder, but the successive cambia still develop in some way. However, this might not be surprising, since the presence of cambial variants in other herbs (annuals or perennials) across the Caryophyllales is commonly observed, suggesting that if given time to grow, most of them can form additional vascular tissue in the form of cambial variants $[69,78]$.

The development and evolution of distinct patterns of cambial variants in Nyctaginaceae is remarkable, because successive cambia was thought to be the only cambial variant in the family [26, 34, 69, 78]. As hypothesized earlier, similar interxylary phloem as observed here may also be present in other caryophyllalean families [32]. As with other traits (e.g., floral morphology [79-81]), the presence of cambial variants likely share developmental and genetic programmes (deep homology) triggering the recurrent evolution of this morphological feature in multiple Caryophyllales lineages.

\section{Evolution of development: how different ontogenies generate similar stem macromorphologies}

Because primary and secondary vascular tissue may have intrinsic developmental relations, the investigation of the diversity and evolution of vascular anatomies in Nyctaginaceae needs to include the products of procambium, cambium and cambial variants to thoroughly comprehend the anatomical and developmental shifts in stem ontogeny. Here the integration between ontogeny and phylogeny showed that adult stems with distinct cambial variants evolved from two different eustele types. Therefore, the evolution of patterns of secondary growth in Nyctaginaceae is built upon distinct primary vascular morphologies.

Evolutionary mechanisms are difficult to be interpreted for the evolution of vascular patterns in Nyctaginaceae because of multiple developmental transitions (Fig. 12). Here, three processes are inferred to generate the stem diversity found in the family (Fig. 12): homeosis, heterochrony, and heterotopy. (1) The formation of interxylary phloem (ontogeny 1) in relation to a putative ancestor with regular anatomy seems likely to represent a case of homeosis, since the unusual activity of 


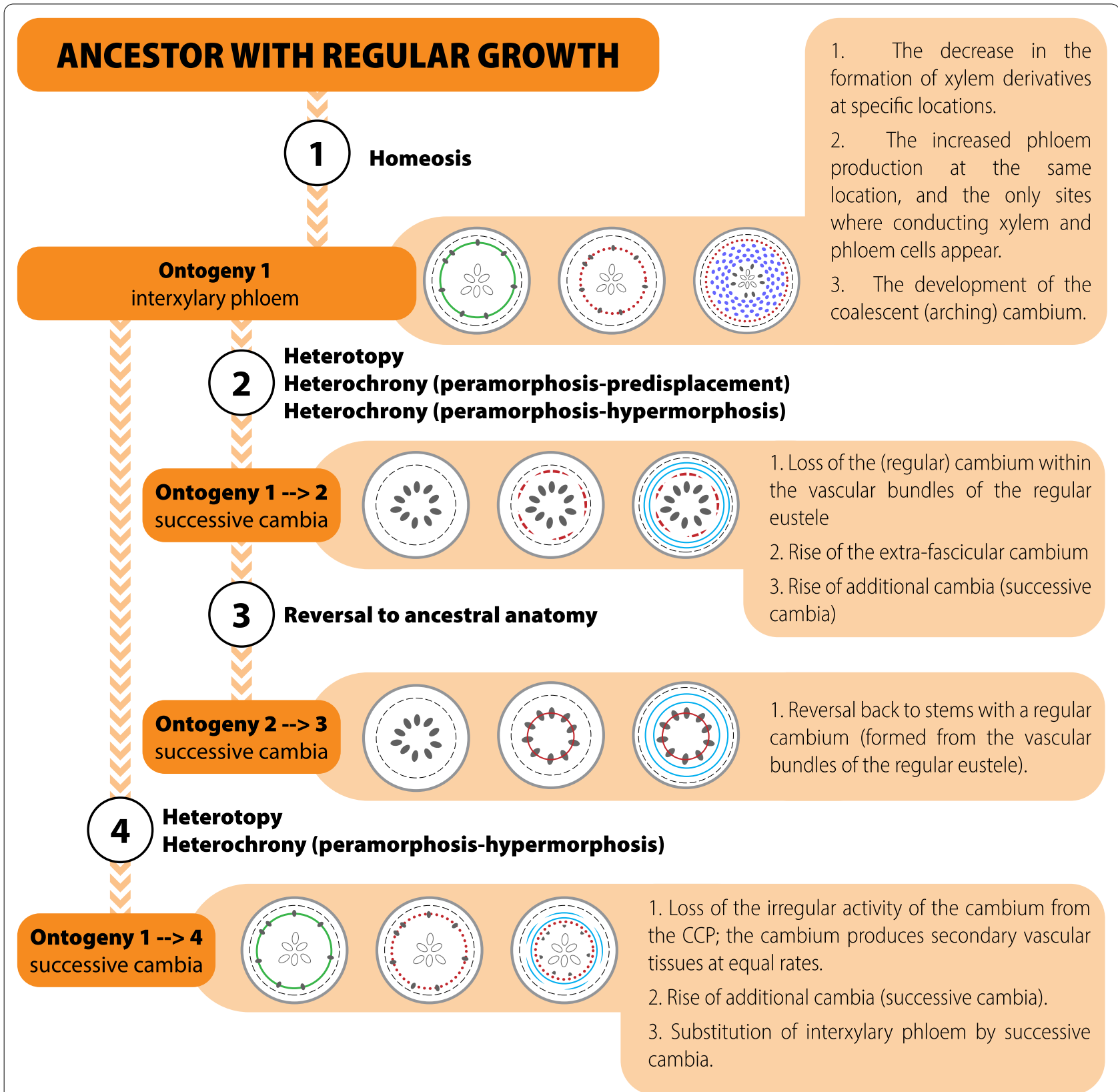

Fig. 12 Overview of the anatomical modifications across evolutionary time in the stem vascular system of Nyctaginaceae and the evolutionary mechanisms generating their complex morphological diversity. Drawing: Marcelo Kubo

the cambium leads to the presence of phloem strands in the place of secondary xylem. Similar cases of homeosis in woody plants has been hypothesized for example in species with parenchymatized xylem, that is, in cases, where non-lignified parenchyma occur where fibres, vessels and lignified axial parenchyma would be present (e.g., lianas, succulents) [7]. (2) In the evolution of ontogeny 2 from ontogeny 1 , the extra-fascicular cambium appeared, suggesting a case of heterotopy, since the first vascular cambium arises in a different position from that present in the ancestor. In addition, at the structural level the development of ontogeny 2 is based on the earlier onset of formation of the cambial variant by suppressing one of the ontogenetic stages (i.e., formation of a cambium from the primary vascular system); therefore, it may also illustrate for the first time a case of predisplacement, a form of peramorphosis (heterochrony). In wood anatomy, most cases of heterochrony suggest the occurrence of prolonged juvenile characteristics into adult forms (paedomorphosis) [7, 
82, 83], and a case of peramorphosis (hypermorphosis-evolution by developmental additions) is also suggested for the origin of successive cambia in Paullinia, Sapindaceae [9]. Moreover, because ontogeny 2 evolved from ontogeny 1 , this transition also requires modifications in the primary vascular system which indicates developmental changes that are regulated by an independent developmental module [84]. Thus, modularity may also be a source for anatomical diversity in this group. The evolution of ontogeny 3 from ontogeny 2 implicates in the appearance of a regular cambium. This transition indicates that a partial regression to the state of the ancestor of the family occurred in this lineage, if we consider that the regular cambium occurs in the same position of the single cambium generating interxylary phloem. Similarly, the evolution of ontogeny 4 requires a reversion from the cambium with unusual activity to the regular cambium, and then a new cambium is formed constituting the successive cambia, which suggests an additional developmental event.

In the context of continuum morphology, we can propose that successive cambia arise from interxylary phloem by topological change of the new cambia differentiation migrating from secondary phloem parenchyma to pericycle (heterotopy), as a homologue of the coalescent cambium, but with a larger extension, so large that they start constituting completely independent additional cambia. Whether these interpretations would hold under a genetic developmental approach is something yet to be explored. These combinations of developmental processes as observed in Nyctaginaceae may be under complex gene regulation, given that multiple cellular and tissue processes are involved in the formation of each cambial variant [32] and that morphological fuzziness results from overlapping developmental programs [57]. In addition, it is likely that the formation of the primary vascular system function as a module independent from the establishment of secondary growth, since different secondary architectures can evolve from distinct pre-vascular conditions in the primary stem.

\section{The impact of transitions in habits, eustele types and cambial variants in the diversification of Nyctaginaceae}

The diversification of Nyctaginaceae was most probably in the Middle Eocene ( $\sim 8 \mathrm{Ma})$, when most of the extant angiosperm families were already established forming the contemporaneous tropical biomes [45]. Other estimates for the split between Nyctaginaceae and close-related families assumes an interval lying between 13 and $33 \mathrm{Ma}$ [85], as inferred for the divergence from Aizoaceae + Phytolaccaceae (e.g., $26 \mathrm{Myr}$, [86]).
Speciation/diversification rate increased in Nyctaginaceae $28.62 \mathrm{Ma}$, at the time of emergence of a group comprising the Bougainvilleeae and Pisonieae ("B\&P") clade + the Nyctagineae ("NAX") clade [35], and has been maintained since then. There is not an apparent unique characteristic for this group that could explain its increase in diversification. However, different hypotheses have been pointed out for the high number of species in each tribe individually. For instance, a remarkable radiation of genera from the NAX clade occurred in deserts of North America, and they are associated with multiple evolutions of cleistogamy and edaphic endemism to grow on gypsum soils [35]; the B\&P clade stands out by having most of the neotropical and large, woody species of the family, which include both the Guapira/Neea/Pisonia trees, as well as the shrubby-scandent or tree species of Bougainvillea [35]. In addition, the evolution of fleshy anthocarps (the fruits of Nyctaginaceae) in the Guapira/ Neea lineage and the likely appearance of endozoochory, seems to be one of the possible explanations for the rapid radiation of taxa of this lineage $[35,36]$.

Commicarpus has experienced a high turnover of species, where many species have been generated but also went extinct, as observed by the rise in both speciation and extinction rate that ultimately involve an increase in the diversification rate. This genus is one of several lineages of Caryophyllales, where a diversification rate shift has been detected, indicating a very recent and rapid radiation [87]. In some other caryophyllalean lineages, genome duplications (polyploidy species) were associated with diversification shifts, which was not identified in Commicarpus in that study sampling. Within the NAX clade, Commicarpus stands out for having few American species and being mostly diverse in Africa, with several species showing restricted distributions (endemics) in tropical regions, some of them also growing on gypsum or limestone [35, 88, 89].

Our results also suggest that there was no increase in diversification rate in the lineages containing lianas (e.g., Bougainvillea, Colignonia), therefore, contradicting previous hypotheses that the evolution of the lianescent habit boosts diversification [30, 31]. This observation is noteworthy, because it indicates with an explicit analysis that higher speciation rates correlated to the evolution of lianas seem not to be a rule, at least when the whole group has a cambial variant, as it is the case of Nyctaginaceae. Indeed, while diversification rate has been directly correlated to lianescent habit in Annonaceae [90], not all lianescent lineages have a rise in diversification rate. On the other hand, we found out that there is a transition from regular to polycyclic eustele in the clade comprising the tribes 
Boldoeae + Colignonieae + Pisonieae + Bougainvillea + Nyctagineae, which is probably the main vascular character associated to an increase in diversification rate (Fig. 11). However, diversification rate shift results obtained with BAMM (Fig. 11) show that a slight increase in diversification rate occurred in a clade comprising Pisonieae + Bougainvillea + Nyctagineae, a less inclusive group compared to Boldoeae + Colignonieae + Pisonieae + Bougainvillea + Nyctagineae observed in the HiSSE results, thus possibly the shift to a polycyclic eustele (medullary bundles) type was a precursor, or a background variable, for diversification rate shift instead of a trigger [91]. This may suggest that other factors, including reproductive traits combined with those analysed here, can be involved in the diversification rate shifts within Nyctaginaceae, such as extrinsic variables, such as habitat occupation. Nevertheless, the occurrence and diversity of variant anatomies in Nyctaginaceae seem to be not contingent on specific habits, since both cambial variants occurs in species with all the range of growth forms present in the family.

\section{Conclusions}

By comparing the stem developments in all main lineages of Nyctaginaceae, we discovered that the mature vascular architectures range from typical successive cambia to interxylary phloem, following four different ontogenies. These ontogenies share developmental stages and thus may contain intermediate forms between the typical state of these two cambial variants. This way, the stem diversity in Nyctaginaceae, which is driven by developmental changes triggered by heterochronic, heterotopic and homeotic processes, may represent a strong case of continuum morphology represented by the evolution of successive cambia from interxylary phloem. Nyctaginaceae is also one of the first groups to show cambial variants in all members of the family, whose ancestor was reconstructed as having interxylary phloem instead of the most endorsed type, successive cambia. These cambial variants are built upon two dissimilar primary vascular organizations, the regular or polycyclic eustele, suggesting that distinct developmental modules are present in the stem ontogeny of these plants. We also presented that high species richness in Nyctaginaceae has probably not been driven by transitions in habits or cambial variants, which indicates that other functional traits, such as the acquisition of medullary bundles, may have been more important in their diversification. Medullary bundles may be advantageous in xerophytic plants, being present in other groups, such as Amaranthaceae and Cactaceae. The complex and diverse developmental pathways shown by Nyctaginaceae may be present in close-related families and be of important phylogenetic significance within Caryophyllales, given the likely potential for convergent evolution in this group. Further investigations in the evolution of development of other caryophyllalean families remain essential in our desire for a better interpretation of the morphological evolution in this lineage. In addition, understanding the genetic regulatory network underlying stem development in Nyctaginaceae seems to be the next step, since it will be easier to identify the role of genes once it is investigated in plants, where the developmental and evolutionary patterns are further comprehended.

\section{Supplementary Information}

The online version contains supplementary material available at https://doi. org/10.1186/s13227-021-00190-1.

Additional file 1: Table S1. List of studied species for all Nyctaginaceae and outgroups.

Additional file 2: Table S2. Character data set used in HiSSE analyses. Additional file 3: Text S1. R script with parameters for HiSSE analyes. Additional file 4: Text S2. Nexus tree used for diversification analyses. Additional file 5: Figure S1. BAMM results or rate shifts in Nyctaginaceae-all most credible shift sets recovered with associate probabilities.

Additional file 6: Table S4. Classification and terminology of successive cambia in different plant families.

\section{Acknowledgements}

We thank Cyl F. Catarino de Sá, Elson Felipe S. Rossetto, Michael H. Nee and Norman A. Douglas for assistance during fieldwork. We are very grateful to the reviewers for their critical reading and valuable comments.

\section{Authors' contributions}

ILCN, MRP and VA designed the study. ILCN, MRP, RHG organized the methodology. ILCN performed the investigation, data curation and wrote the manuscript. ILCN and RHG carried out diversification analysis and prepared data presentation. All authors read and approved the final manuscript.

\section{Funding}

This study was supported by the São Paulo Research Foundation-FAPESP (Process 2017/17107-3) to ILCN and by the Coordenação de Aperfeiçoamento de Pessoal de Nível Superior_Brasil (CAPES)_Finance Code 001, and DGAPA PAPIIT in Mexico (IA200521) to MRP.

Availability of data and materials

The data set(s) supporting the conclusions of this article are available at https://github.com/ilcneto/Stem_Evolution_Nyctaginaceae. All supporting data are available in Additional files.

\section{Declarations}

Ethics approval and consent to participate Not applicable.

Consent for publication

All authors have provided consent for publication.

Competing interests

The authors declare that they have no competing interests. 
Glossary

Term
Cambial variant
Cambium
Cambium from the continuous
cylindrical procambium (CCP)
Coalescent (arching) cambium

Conjunctive tissue

Continuous cylindrical procambium (CCP)

Extra-fascicular cambium

Interxylary phloem

Medullary bundles

Meristematic zone

Polycyclic eustele

\section{Definition}

Vascular anatomy in mature stems distinct from the so-called 'regular secondary growth' (see definition below).

Lateral meristem composed of cells actively dividing to maintain themselves, and to produce both secondary xylem and phloem.

In polycyclic steles, cambium originated from the outermost ring of vascular bundles.

In stems with interxylary phloem, fragment of cambium originated through redifferentiation of secondary phloem parenchyma cells encapsulating a portion of phloem and cambium; this (arching) cambium typically connects with the single main cambium at both ends.

In species with successive cambia, parenchymatous or sclerified tissue between vascular rings derived from the meristematic zones.

In stems with polycyclic eusteles, ring of procambial cells which originates vascular bundles and delimits the pith containing medullary bundles; after differentiation of the bundles, the CCP may be divided into fascicular and interfascicular procambia.

First cambium of some stems which is formed outside the vascular bundles of the eustele in a pericyclic region.

Cambial variant formed through the activity of a single cambium, producing strands of secondary phloem embedded within the secondary xylem.

Vascular bundles scattered in the pith, derived from vascular traces of lateral appendages (e.g. leaves, thorns); the bundles usually undergo secondary growth forming secondary axial and radial tissues; in this case they may be named as vascular fascicule.

In species with successive cambia, the group of cells with meristematic activity produced from divisions of the pericycle (cortex or phloem in other taxa) that originates a new cambium, and conjunctive tissue.

Eustele formed by medullary bundles scattered in the pith and surrounded by a CCP and their derived vascular bundles.
Regular cambium

Formed from both procambial remnants between primary xylem and phloem (at the vascular bundle) and adjacent (pericyclic) parenchyma. The most common secondary growth mode in woody plants.

Regular cylinder

The main cylinder of secondary xylem and phloem formed by either the cambium from the CCP or the regular cambium; in the latter, it may also be referred as central cylinder.

Regular eustele Primary vascular system formed by a discrete cylinder of vascular bundles delimiting the pith.

Regular growth

Ancestral secondary growth mode of the Lignophytes, i.e., by means of a bifacial cambium producing secondary xylem inwards and secondary phloem outwards, at homogeneous rate generating a single vascular cylinder.

Sheathing axial parenchyma (SAP) Axial phloem parenchyma surrounding the interxylary conducting phloem.

Successive cambia

Cambial variant type formed by one or more patches or rings of additional vascular cambia and their products.

Variant cambium

Cambium originated in an unusual position and/or with an activity different from the most common in woody plants. This difference can be in rate, extension, or products. They originate cambial variants.

\section{Author details}

${ }^{1}$ Laboratório de Anatomia Vegetal, Departamento de Botânica, Instituto de Biociências, Universidade de São Paulo, Rua do Matão 277, São Paulo, SP, Brazil. ${ }^{2}$ School of Integrative Plant Sciences and L.H. Bailey Hortorium, Cornell University, Ithaca, NY 14853, USA. ${ }^{3}$ Departamento de Botánica, Instituto de Biología, Universidad Nacional Autónoma de México, Ciudad Universitaria, Circuito Zona Deportiva s/n, Ciudad Universitaria, 04510 Coyoacán, Mexico City, Mexico.

Received: 7 October 2021 Accepted: 22 December 2021

Published online: 29 January 2022

\section{References}

1. Gilbert SF. The morphogenesis of evolutionary developmental biology. Int J Dev Biol. 2003;47:467-77.

2. Arthur $W$. The effect of development on the direction of evolution: toward a twenty-first century consensus. Evol Dev. 2004;6:282-8.

3. Sattler R. Homology, homeosis, and process morphology in plants. In: Hall BK, editor. The hierarchical basis of comparative biology. New York: Academic Press; 1994. p. 423-75.

4. Rutishauser R, Moline P. Evo-devo and the search for homology ("sameness") in biological systems. Theory Biosci. 2005;124:213-41.

5. Hall BK. Evolutionary developmental biology (evo-devo): past, present, and future. Evol Educ Outreach. 2012;5:184-93. 
6. Olson ME, Rosell JA. Using heterochrony to detect modularity in the evolution of stem diversity in the plant family Moringaceae. Evolution. 2006:60:724-34

7. Olson ME. Wood ontogeny as a model for studying heterochrony, with an example of paedomorphosis in Moringa (Moringaceae). Syst Biodivers. 2007;5:145-58.

8. Pace MR, Lohmann LG, Angyalossy V. The rise and evolution of the cambial variant in Bignonieae (Bignoniaceae). Evol Dev. 2009;11:465-79.

9. Chery JG, Pace MR, Acevedo-Rodríguez P, Specht CD, Rothfels CJ. Modifications during early plant development promote the evolution of nature's most complex woods. Curr Biol. 2020;30:237-244.e2.

10. Taylor T. Progymnosperms. Biol Evol Foss Plants. 2009;483:479-502.

11. Simpson MG. Plant systematics. 2nd ed. San Diego: Elsevier Academic Press; 2010

12. Crepet WL, Niklas KJ. The evolution of early vascular plant complexity. Int J Plant Sci. 2019;180:800-10.

13. Rudall P. Lateral meristems and stem thickening growth in monocotyledons. Bot Rev. 1991;57:150-63.

14. Willis KJ, McElwain JC. The evolution of plants. New York: Oxford; 2002.

15. Spicer R, Groover A. Evolution of development of vascular cambia and secondary growth. New Phytol. 2010;186:577-92.

16. Zinkgraf M, Gerttula S, Groover A. Transcript profiling of a novel plant meristem, the monocot cambium. J Integr Plant Biol. 2017;59:436-49.

17. Carlquist S. Anatomy of vine and liana stems: a review and synthesis. In: Putz FE, Mooney HA, editors. The biology of vines. New York: Univ. Cambridge Press; 1991. p. 53-72.

18. Angyalossy $V$, Angeles G, Pace MR, Lima AC, Dias-Leme CL, Lohmann LG, et al. An overview of the anatomy, development and evolution of the vascular system of lianas. Plant Ecol Divers. 2012;5:167-82.

19. Angyalossy V, Angeles G, Pace M, Lima A. Liana anatomy: a broad perspective on structural evolution of the vascular system. In: Schnitzer SA, Bongers F, Burnham RJ, editors. Ecology of lianas. Chinchester: Wiley; 2015. p. 253-87.

20. Schweingruber FH, Börner A, Schulze E-D. Atlas of stem anatomy in herbs, shrubs and trees. Berlin: Springer; 2011.

21. Hernández-Ledesma P, Berendsohn WG, Borsch T, Von Mering S, Akhani $H$, Arias $S$, et al. A taxonomic backbone for the global synthesis of species diversity in the angiosperm order Caryophyllales. Willdenowia. 2015;45:281-383

22. Douglas N, Spellenberg R. A new tribal classification of Nyctaginaceae. Taxon. 2010;59:905-10.

23. Cunha Neto IL, Pace MR, Douglas NA, Nee MH, de Sá CFC, Moore MJ, et al. Diversity, distribution, development, and evolution of medullary bundles in Nyctaginaceae. Am J Bot. 2020;107:707-25.

24. De Bary A. Comparative anatomy of the vegetative organs of the phanerogams and ferns. Oxford: Clarendon Press; 1884.

25. Esau K, Cheadle VI. Secondary growth in Bougainvillea. Ann Bot 1969;33:807-19.

26. Carlquist S. Lateral meristems, successive cambia and their products: Nyctaginaceae. Bot J Linn Soc. 2004;146:129-43.

27. Pace MR. Evolution of the vascular system in lineages that contain lianas. São Paulo: University of São Paulo; 2015

28. Acevedo-Rodríguez P. Lianas and climbing plants of the Neotropics. 2015. https://naturalhistory.si.edu/research/botany/research/lianas-and-climb ing-plants-neotropics.

29. Terrazas T, Aguilar-Rodríguez S, Ojanguren CT. Development of successive cambia, cambial activity, and their relationship to physiological traits in Ipomoea arborescens (Convolvulaceae) seedlings. Am J Bot. 2011;98:765-74.

30. Gianoli E. Evolution of a climbing habit promotes diversification in flowering plants. Proc R Soc B Biol Sci. 2004;271:2011-5.

31. Gianoli E. Evolutionary implications of the climbing habit in plant. In: Schnitzer SA, Bongers F, Burnham RJ, Putz FE, editors. Ecology of lianas. West Sussex: Wiley; 2015. p. 239-50.

32. Cunha Neto IL, Pace MR, Angyalossy V. A new interpretation of the successive cambia of some Nyctaginaceae as interxylary phloem. Int J Plant Sci. 2021;182:620-37.

33. Rajput KS, Patil VS, Kapadne KK. Structure and development of secondary thickening meristem in Mirabilis jalapa (Nyctaginaceae). Polish Bot J. 2009;54:113-21.
34. Hernández-Ledesma P, Terrazas T, Flores-Olvera H. Comparative stem anatomy of Mirabilis (Nyctaginaceae). Plant Syst Evol. 2011;292:117-32.

35. Douglas N, Manos PS. Molecular phylogeny of Nyctaginaceae: taxonomy, radiation of xerophytic genera in North America. Am J Bot. 2007:94:856-72.

36. Rossetto EFS, De Faria AD, Ruas PM, Ruas CDF, Douglas NA, Ribeiro JELDS. Clarifying generic delimitation in Nyctaginaceae tribe Pisonieae after more than a century of taxonomic confusion. Bot J Linn Soc. 2019;189:378-96.

37. Johansen DA. Plant microtechnique. New York: MacGraw-Hill Book; 1940

38. O'Brien TP, Feder N, Mac Cully MW. Polychromatic staining of plant cell walls by toluidine blue O. Protoplasma. 1964;59:368-73.

39. Carlquist S. The use of Ethylenediamine in softening hard plant. Stain Technol. 1982:57:311-7.

40. Barbosa ACF, Pace MR, Witovisk L, Angyalossy V. A new method to obtain good anatomical slides of heterogeneous plant parts. IAWA J. 2010;31:373-83.

41. Barbosa ACF, Costa GRO, Angyalossy V, Dos Santos TC, Pace MR. A simple and inexpensive method for sharpening permanent steel knives with sandpaper. IAWA J. 2018:39:497-503.

42. Bukatsch F. Bemerkungen zur Doppelfärbung Astrablau-Safranin. Mikrokosmos. 1972:61:255.

43. Maddison WP, Maddison DR. Mesquite: a modular system for evolutionary analysis. 2019. http://www.mesquiteproject.org.

44. Bouckaert R, Heled J, Kühnert D, Vaughan T, Wu CH, Xie D, et al. BEAST 2: a software platform for Bayesian evolutionary analysis. PLoS Comput Biol. 2014;10:1-6.

45. Ramírez-Barahona S, Sauquet H, Magallón S. The delayed and geographically heterogeneous diversification of flowering plant families. Nat Ecol Evol. 2020;4:1232-8.

46. Drummond AJ, Ho SYW, Phillips MJ, Rambaut A. Relaxed phylogenetics and dating with confidence. PLoS Biol. 2006;4:699-710.

47. Rambaut A, Suchard MA, Xie D, Drummond AJ. Tracer v1.6. 2014. http://tree.bio.ed.ac.uk/software/tracer/.

48. Magallón S, Sanderson MJ. Absolute diversification rates in angiosperm clades. Evolution. 2001:55:1762-80.

49. Morlon $\mathrm{H}$. Phylogenetic approaches for studying diversification. Ecol Lett. 2014:17:508-25.

50. Rabosky DL. Automatic detection of key innovations, rate shifts, and diversity-dependence on phylogenetic trees. PLoS ONE. 2014;9: e89543.

51. Rabosky DL, Grundler M, Anderson C, Title P, Shi JJ, Brown JW, et al. BAMMtools: an R package for the analysis of evolutionary dynamics on phylogenetic trees. Methods Ecol Evol. 2014;5:701-7.

52. R Core Team. R: A Language and environment for statistical computing. Vienna, Austria: R Foundation for Statistical Computing; 2021. https:// www.r-project.org/.

53. Plummer M, Best N, Cowles K, Vines K. coda: convergence diagnosis and output analysis for MCMC. R News. 2006;6:7-11. http://cran.r-project.org/ doc/\%0ARnews/.

54. Beaulieu JM, O'Meara BC. Detecting hidden diversification shifts in models of trait-dependent speciation and extinction. Syst Biol. 2016;65:583-601.

55. Maddison WP, Midford PE, Otto SP. Estimating a binary character's effect on speciation and extinction. Syst Biol. 2007;56:701-10.

56. Cunha Neto IL, Silva JP, Angyalossy V. Anatomy of vegetative organs in Allionia (Nyctaginaceae), with emphasis on the vascular system. J Bot Res Inst Texas. 2020;15:373-94.

57. Rutishauser R. EvoDevo: past and future of continuum and process plant morphology. Philosophies. 2020;5:41.

58. Claßen-Bockhoff R. Plant morphology: the historic concepts of Wilhelm Troll, Walter Zimmermann and Agnes Arber. Ann Bot. 2001;88:1153-72.

59. Arber A. The natural philosophy of plant form. Cambridge: Cambridge University Press; 1950

60. Sattler R. Classical morphology and continuum morphology: opposition and continuum. Ann Bot. 1996;78:577-81.

61. Sattler R. Towards a more adequate approach to comparative morphology. Phytomorphology. 1966;16:417-29.

62. Göbel CY, Schlumpberger BO, Zotz G. What is a pseudobulb? Toward a quantitative definition. Int J Plant Sci. 2020;181:686-96. 
63. Teixeira-Costa L. A living bridge between two enemies: haustorium structure and evolution across parasitic flowering plants. Rev Bras Bot 2021;44:165-78. https://doi.org/10.1007/s40415-021-00704-0.

64. Cruz R, Prado J, Flávia G, Melo-De-Pinna A. Leaf development in some ferns with variable dissection patterns (Dryopteridaceae and Lomariopsidaceae). Flora. 2020. https://doi.org/10.1016/j.flora.2020.151658.

65. Rutishauser R. Evolution of unusual morphologies in Lentibulariaceae (bladderworts and allies) and Podostemaceae (river-weeds): a pictorial report at the interface of developmental biology and morphological diversification. Ann Bot. 2016;117:811-32.

66. Zhang K-Y, Yang D, Zhang Y-B, Ellsworth DS, Xu K, Zhang Y-P, et al. Differentiation in stem and leaf traits among sympatric lianas, scandent shrubs and trees in a subalpine cold temperate forest. Tree Physiol. 2021;41:1992-2003.

67. Messerschmid TFE, Wehling J, Bobon N, Kahmen A, Klak C, Los JA, et al. Carbon isotope composition of plant photosynthetic tissues reflects a Crassulacean acid metabolism (CAM) continuum in the majority of CAM lineages. Perspect Plant Ecol Evol Syst. 2021;51: 125619. https://doi.org/ 10.1016/j.ppees.2021.125619.

68. Carlquist S. Successive cambia revisited: ontogeny, histology, diversity, and functional significance. J Torrey Bot Soc. 2007;134:301-32.

69. Carlquist S. Caryophyllales: a key group for understanding wood anatomy character states and their evolution. Bot J Linn Soc. 2010;164:342-93.

70. Phillips B. Anatomy and developmental morphology of Allionia L. (Nyctaginaceae). Tucson: The University of Arizona; 1976.

71. Tamaio N, Vieira RC, Angyalossy V. Origin of successive cambia on stem in three species of Menispermaceae. Rev Bras Botânica. 2009;32:839-48.

72. Cunha Neto IL, Martins FM, Somner GV, Tamaio N. Successive cambia in liana stems of Paullinieae and their evolutionary significance in Sapindaceae. Bot J Linn Soc. 2018;186:66-88.

73. Pace MR, Angyalossy V, Acevedo-Rodríguez P, Wen J. Structure and ontogeny of successive cambia in Tetrastigma (Vitaceae), the host plants of Rafflesiaceae. J Syst Evol. 2018;56:394-400.

74. Leme CLD, Cunha Neto IL, Angyalossy V. How the neotropical liana Machaerium multifoliolatum (Fabaceae) develop their distinctive flattened stems? Flora Morphol Distrib Funct Ecol Plants. 2020;269: 151629. https:// doi.org/10.1016/j.flora.2020.151629.

75. Rajput KS, Nunes OM, Brandes AFN, Tamaio N. Development of successive cambia and pattern of secondary growth in the stem of the Neotropical liana Rhynchosia phaseoloides (SW.) DC. (Fabaceae). Flora Morphol Distrib Funct Ecol Plants. 2012;207:607-14. https://doi.org/10.1016/j.flora. 2012.04.001.

76. Myśkow E, Gola EM, Tulik M. Continuity of procambium and anomalous cambium during formation of successive cambia in Celosia argentea. J Plant Growth Regul. 2019;38:1458-66.

77. Pace MR. Evolution of the vascular system in lineages that contain lianas. Ph.D. thesis, University of São Paulo, São Paulo. 2015.

78. Schwallier R, Gravendeel B, De Boer H, Nylinder S, Van Heuven BJ, Sieder $A$, et al. Evolution of wood anatomical characters in Nepenthes and close relatives of Caryophyllales. Ann Bot. 2017;119:1179-93.

79. Brockington S, Dos Santos P, Glover B, De Craene LR. Androecial evolution in Caryophyllales in light of a paraphyletic Molluginaceae. Am J Bot. 2013;100:1757-78.

80. Ronse De Craene LP. Reevaluation of the perianth and androecium in Caryophyllales: implications for flower evolution. Plant Syst Evol. 2013;299:1599-636.

81. Ronse de Craene LP. Gynoecium structure and development in core Caryophyllales: a matter of proportions. Bot J Linn Soc. 2021;195:437-66.

82. Carlquist S. Xylem heterochrony: an unappreciated key to angiosperm origin and diversifications. Bot J Linn Soc. 2009;161:26-65.

83. Carlquist S. More woodiness/less woodiness: evolutionary avenues, ontogenetic mechanisms. Int J Plant Sci. 2013;174:964-91.

84. Tomescu AMF, Groover AT. Mosaic modularity: an updated perspective and research agenda for the evolution of vascular cambial growth. New Phytol. 2019;222:1719-35.

85. Hayward J, Horton TR. Phylogenetic trait conservation in the partner choice of a group of ectomycorrhizal trees. Mol Ecol. 2014;23:4886-98.

86. Klak C, Reeves G, Hedderson T. Unmatched tempo of evolution in Southern African semi-desert ice plants. Nature. 2004;427:63-5.
87. Smith SA, Brown JW, Yang Y, Bruenn R, Drummond CP, Brockington SF, et al. Disparity, diversity, and duplications in the Caryophyllales. New Phytol. 2018;217:836-54.

88. Thulin M. Four new species of Commicarpus (Nyctaginaceae) from NE tropical Africa. Nord J Bot. 1990;10:403-9.

89. Friis I, Gilbert MG, Weber O, Demissew S. Two distinctive new species of Commicarpus (Nyctaginaceae) from gypsum outcrops in eastern Ethiopia. Kew Bull. 2016;71:1-19.

90. Xue B, Guo X, Landis JB, Sun M, Tang CC, Soltis PS, et al. Accelerated diversification correlated with functional traits shapes extant diversity of the early divergent angiosperm family Annonaceae. Mol Phylogenet Evol. 2020;142: 106659. https://doi.org/10.1016/j.ympev.2019.106659.

91. Bouchenak-Khelladi Y, Onstein RE, Xing Y, Schwery O, Linder HP. On the complexity of triggering evolutionary radiations. New Phytol. 2015;207:313-26.

\section{Publisher's Note}

Springer Nature remains neutral with regard to jurisdictional claims in published maps and institutional affiliations.

Ready to submit your research? Choose BMC and benefit from:

- fast, convenient online submission

- thorough peer review by experienced researchers in your field

- rapid publication on acceptance

- support for research data, including large and complex data types

- gold Open Access which fosters wider collaboration and increased citations

- maximum visibility for your research: over 100M website views per year

At BMC, research is always in progress.

Learn more biomedcentral.com/submissions 